\title{
AN INTEGRATED MULTI-CRITERIA DECISION-MAKING FRAMEWORK FOR SUSTAINABLE SUPPLIER SELECTION UNDER PICTURE FUZZY ENVIRONMENT
}

\author{
Juan-juan PENG ${ }^{1}$, Chao TIAN ${ }^{*}$, Wen-yu ZHANG ${ }^{1}$, \\ Shuai $\mathrm{ZHANG}^{1}$, Jian-qiang WANG ${ }^{2}$ \\ ${ }^{1}$ School of Information, Zhejiang University of Finance \& Economics, 310018 Hangzhou, China \\ ${ }^{2}$ School of Business, Central South University, 410083 Changsha, China
}

Received 30 May 2019; accepted 16 January 2020

\begin{abstract}
Sustainable supplier selection (SSS) is an important part of sustainable supply chain management (SSCM). In this paper, an integrated multi-criteria decision-making (MCDM) framework, based on the picture fuzzy exponential entropy, and the VIsekriterijumska optimizacija i KOmpromisno Resenje (VIKOR) method, is proposed to manage SSS problems. Firstly, the evaluation criteria of SSS, including economic, environmental and social, is established. This can be evaluated in the form of the actual data or linguistic terms provided by suppliers and experts respectively in an actual decision-making process. Then, according to the translated scales, all the evaluation information can be converted into picture fuzzy numbers (PFNs). Secondly, the picture fuzzy exponential entropy is defined. Moreover, based on the entropy's minimization principle, the defined picture fuzzy exponential entropy is used to determine the weight of the SSS's criteria. Thirdly, the extended VIKOR method, which combines the grey correlation coefficient, is utilized to select a suitable supplier. This method avoids the shortcomings of the traditional VIKOR method in data mining and solves the conflict between SSS criteria. Finally, the feasibility and effectiveness of the proposed integrated decision framework are verified by an experiment, as well as a sensitivity analysis and comparative analysis.
\end{abstract}

Keywords: sustainable supplier selection, multi-criteria decision-making, picture fuzzy numbers, VIKOR, exponential entropy.

JEL Classification: D81, C61, Q56.

\section{Introduction}

Due to the depletion of natural resources, environmental pollution, labor safety and other issues becoming increasingly prominent, modern enterprises pay increasing attention to sustainable development. In other words, enterprises should maximize their economic benefits,

\footnotetext{
${ }^{\star}$ Corresponding author. E-mail: 201682@csu.edu.cn
}

\section{(C) 2020 The Author(s). Published by VGTU Press}

This is an Open Access article distributed under the terms of the Creative Commons Attribution License (http://creativecommons. org/licenses/by/4.0/), which permits unrestricted use, distribution, and reproduction in any medium, provided the original author and source are credited. 
whilst also having certain environmental responsibility and social responsibilities. Moreover, sustainable supply chain management (SSCM) requires the effective integration of all those involved in the supply chain, such as raw material suppliers, manufacturers, dealers, retailers, logistics companies and consumers. This will coordinate economic, environmental and social benefits effectively, to maximize the overall benefits (Hassini et al., 2012).

Sustainable supplier selection (SSS) is an important part of SSCM. The performance of suppliers not only affects the producers' performance, but also affects the performance of downstream enterprises (Mou et al., 2018). Therefore, SSS is a key factor for enterprises seeking to achieve sustainable development. Compared with the traditional supplier selection process, SSS should not only consider a supplier's economic performance, such as product quality, price, transportation, after-sales service and production management, but also consider their environmental protection, energy-saving performance and social responsibility.

Therefore, the rationale of this paper is threefold. Firstly, picture fuzzy numbers (PFNs), involving the degrees of positive, neutral, negative and refuse, can better depict uncertainty in a subjective evaluation of decision-makers (DMs). Secondly, DMs should categorize candidate suppliers and experts simultaneously, with the evaluation values being in the form of the actual data and subjective linguistic terms provided by the candidate suppliers and experts respectively. This can make the final results more consistent with actual decision-making by combining a quantitative and qualitative evaluation. Thirdly, there is often competition and conflict between the SSS's criteria, and the VIsekriterijumska optimizacija i KOmpromisno Resenje (VIKOR) method (Opricovic \& Tzeng, 2004) has the advantages of considering the maximization of group utility and the minimization of individual regret, as well as incorporating the subjective preference of DMs. Moreover, a grey relation analysis can avoid the drawbacks of the traditional VIKOR method. However, most of the existing methods only consider the evaluation value of the criteria to be a single type, and research on different types of criteria is poor. Thus, this paper constructs an integrated multi-criteria decisionmaking (MCDM) framework, based on the picture fuzzy exponential entropy measure and the extended VIKOR method, to resolve SSS problems where the criteria's weight information is completely unknown. Moreover, the picture fuzzy exponential entropy method can be used to obtain the weight of the SSS's criteria, while the extended VIKOR method is utilized to rank sustainable suppliers.

Accordingly, the rest of this paper is structured as follows. In Section 1, a literature review is conducted. In Section 2, the picture fuzzy exponential entropy is defined and the corresponding properties are discussed. Section 3 develops the MCDM framework with picture fuzzy information to solve SSS problems. An experimental analysis is provided to testify the developed approach's validity and effectiveness in Section 4. Finally, the management implications are outlined and conclusions are drawn in Section 6 and last section respectively. 


\section{Literature review}

The extant research on SSS problems mainly focuses on the evaluation criteria and evaluation methods.

\subsection{The evaluation criteria}

Constructing a set of scientific and feasible evaluation criteria of SSS is an important way of achieving the optimal supplier selection. Recently, many scholars have studied the evaluation criteria of SSS. Moreover, based on the SSCM principle, existing studies have shown that the evaluation criteria of SSS should observe the triple bottom line, i.e., it should include three aspects: economic, environmental and social (Elkington, 1998). The economic criteria are the maximum income set against the minimum input, and are mainly related to product cost, quality, production capacity, and technical capability (Weber et al., 1991; Yu \& Wong, 2015; Goren, 2018). The environmental criteria mainly refer to the problems of product pollution and energy conversation, and include eco-design, green raw materials, pollution and recycling (Roostaee et al., 2012; Yu et al., 2019). The social criteria are mainly related to issues such as health and safety standards, corporate disclosure, and corporate reputation (Roostaee et al., 2012; Liu et al., 2018).

This paper summarizes the existing literature on the evaluation criteria of the three layers of SSS, including the corresponding criteria and sub-criteria, the measurement of the criteria, the criteria's attributes, and the type of the criteria's evaluation value (as shown in Table 1). The first layer is the target layer, i.e., the evaluation criteria of SSS; it consists of the three main criteria, economic, environmental, and social. Moreover, the specific factors influencing partner selection are based on the second level of the index system, which also consists of the three criteria. The three main criteria reflect an important aspect of the evaluation of SSS, and the corresponding sub-criteria are established at the third level as shown in Table 1. The enterprises can reduce or increase the corresponding sub-criteria according to the specific circumstances of SSS problems.

\subsection{The evaluation methods}

Many evaluation methods for SSS have recently been proposed, which can be classified into three categories.

The first class is the combination of the fuzzy analytic hierarchy process (AHP) and MCDM method. For example, Weber and Desai (1996) and Aghdaie (2017) applied the AHP to supplier selection problems, whilst Sanayei et al. (2010) and Kuo et al. (2010) developed an integrated method by combining the artificial neural network and MCDM method. Furthermore, Roostaee et al. (2012) combined fuzzy sets (FSs) and intuitionistic fuzzy sets (IFSs) with the VIKOR method. Alimardani et al. (2013) developed a methodology based on the VIKOR method for supplier selection. Scott et al. (2014) integrated an AHP-QFD (Quality Function Deployment). Liu et al. (2018) defined an Analytic Network Process (ANP)-VIKOR method and Xu et al. (2019) developed an AHPSort II method under an interval type-2 fuzzy environment. Awasthi et al. (2018) developed a fuzzy AHP-VIKOR method and Memari 
et al. (2019) developed an intuitionstic fuzzy Technique for Order of Preference by Similarity to Ideal Solution (TOPSIS) method for SSS. Finally, Chaharsooghi and Ashrafi (2014) developed a Neofuzzy TOPSIS method with triangular fuzzy numbers (TFNs).

The second class of evaluation methods for SSS is mainly based on the optimization model. For instance, Zhou et al. (2016) established a multi-objective data envelopment analysis

Table 1 . The evaluation criteria

\begin{tabular}{|c|c|c|c|c|}
\hline Criteria & Sub-criterion & Measurement & Attribute & $\begin{array}{l}\text { Type } \\
\text { of value }\end{array}$ \\
\hline \multirow{6}{*}{$\begin{array}{l}\text { Economic } \\
\text { (Elkington, 1998; } \\
\text { Hassini et al., } \\
\text { 2012; Liu et al., } \\
\text { 2018; Mou et al., } \\
\text { 2018; Osiro et al., } \\
\text { 2018) }\end{array}$} & Quality $c_{1}$ & Overall quality of products & Benefit & Accurate \\
\hline & Cost $c_{2}$ & $\begin{array}{l}\text { Price and the share of transaction } \\
\text { costs per unit product }\end{array}$ & Cost & Accurate \\
\hline & $\begin{array}{l}\text { Production } \\
\text { capacity } c_{3}\end{array}$ & Single-shift production per day & Benefit & Accurate \\
\hline & $\begin{array}{l}\text { Technical } \\
\text { capability } c_{4}\end{array}$ & New technical capability & Benefit & Linguistic \\
\hline & $\begin{array}{l}\text { On-time delivery } \\
\text { rate } c_{5}\end{array}$ & On-time delivery rate & Benefit & Accurate \\
\hline & Finance $c_{6}$ & Asset-liability ratio & Cost & Accurate \\
\hline \multirow{5}{*}{$\begin{array}{l}\text { Environmental } \\
\text { (Roostaee et al., } \\
\text { 2012; Trapp \& } \\
\text { Sarkis, 2016; } \\
\text { Liu et al., 2018; } \\
\text { Mou et al., 2018; } \\
\text { Osiro et al., 2018; } \\
\text { Memaria et al., } \\
\text { 2019) }\end{array}$} & Eco-design $c_{7}$ & $\begin{array}{l}\text { Design of products for reduced } \\
\text { consumption of material/energy, } \\
\text { design of products for reuse and } \\
\text { recycling. }\end{array}$ & Benefit & Linguistic \\
\hline & $\begin{array}{l}\text { Sustainable } \\
\text { materials } c_{8}\end{array}$ & $\begin{array}{l}\text { The level of sustainable } \\
\text { materials used in packaging and } \\
\text { manufacturing per product. }\end{array}$ & Benefit & Accurate \\
\hline & Pollution $c_{9}$ & $\begin{array}{l}\text { The average volume of air pollutants, } \\
\text { waste, solid waste, and harmful } \\
\text { materials which can be released per } \\
\text { day during the measurement period }\end{array}$ & Cost & Accurate \\
\hline & $\begin{array}{l}\text { Environmentally- } \\
\text { friendly } \\
\text { technology } c_{10}\end{array}$ & $\begin{array}{l}\text { The use of an environmentally- } \\
\text { friendly technology to conserve the } \\
\text { natural environment and resources }\end{array}$ & Benefit & Linguistic \\
\hline & $\begin{array}{l}\text { Environmental } \\
\text { protection } \\
\text { management } \\
\text { system } c_{11}\end{array}$ & $\begin{array}{l}\text { Environmental certification } \\
\text { conditions such as IS14000, } \\
\text { environmental policy, environmental } \\
\text { target planning, inspection and } \\
\text { control of environmental activities }\end{array}$ & Benefit & Linguistic \\
\hline \multirow{3}{*}{$\begin{array}{l}\text { Social } \\
\text { (Roostaee et al., } \\
\text { 2012; Sarkis \& } \\
\text { Dhavale, 2015; } \\
\text { Trapp \& Sarkis, } \\
\text { 2016; Awasthi } \\
\text { et al., 2018; Mou } \\
\text { et al., 2018; Osiro } \\
\text { et al., 2018; } \\
\text { Memaria et al., } \\
\text { 2019) }\end{array}$} & $\begin{array}{l}\text { Health and safety } \\
c_{12}\end{array}$ & $\begin{array}{l}\text { Including Occupational Safety and } \\
\text { Health (OHSAS) 18001, conditions } \\
\text { and incidents }\end{array}$ & Benefit & Linguistic \\
\hline & $\begin{array}{l}\text { Information } \\
\text { disclosure } c_{13}\end{array}$ & $\begin{array}{l}\text { To provide society with business } \\
\text { information, including financial, } \\
\text { raw material use and pollutant } \\
\text { emissions. }\end{array}$ & Benefit & Linguistic \\
\hline & $\begin{array}{l}\text { Industry } \\
\text { reputation } c_{14}\end{array}$ & $\begin{array}{l}\text { The degree of social recognition of } \\
\text { corporate behavior. }\end{array}$ & Benefit & Linguistic \\
\hline
\end{tabular}


(DEA) model, Trapp and Sarkis (2016) constructed a binary integer programming model, and Tavana et al. (2017) established a goal programming model for SSS respectively. Additionally, Cheraghalipour and Farsad (2018) constructed a bi-objective programming model for SSS and order allocation.

The third class is based on other uncertain theories. For example: Bai and Sarkis (2010) developed an integrated method based on grey theory and rough sets for SSS; Sarkis and Dhavale (2015) developed a method based on the Monte Carlo Markov Chain for SSS; and Osiro et al. (2018) defined a MCDM method based on QFD for SSS.

From the analysis presented above, it can be concluded that the methods outlined can deal effectively with SSS problems. However, further improvement is needed in some aspects. Firstly, the traditional AHP and ANP methods need to provide specific values during [1,9], ignoring the fuzzy and uncertain characteristics of the preference information provided by DMs, and do always not consider the weightings of DMs. Secondly, most existing methods assume that all criteria are evaluated subjectively by DMs, without considering that some criteria can be evaluated by the actual accurate values provided by candidate suppliers, which leads to great differences between the decision-making result and the actual decision-making. In other words, the evaluation process will be more feasible as it involves the candidate suppliers in the evaluation process of SSS. Thirdly, the existing VIKOR methods for SSS are only an extension of traditional methods, and do not consider the shortcomings in data mining.

\section{Preliminaries}

Recently, FSs (Zadeh, 1965) and their extensions have been successfully applied to various fields (Peng et al., 2019; Liu et al. 2019a, 2019b; Shen et al. 2019a, 2019b) and fuzzy evaluation (Shen \& Wang, 2018). As society has developed and research problems have become more complex, the single membership has been restricted in any practical application. Therefore, IFSs (Atanassov, 1986), which are extensions of FSs, were developed and applied to solve MCDM problems (Kannan et al., 2015; Beskese et al., 2018; Liu et al., 2019b; Luo et al., 2019).

\subsection{PFSs}

Picture fuzzy sets (PFSs) (Cuong \& Kreinovich, 2013) as an extension of IFSs, are expressed by the membership, neutral membership and non-membership simultaneously. PFSs can describe the DMs' preference accurately, which can avoid missing information and make the evaluation information more feasible than IFSs. Recent research on PFSs has focused on its extensions and MCDM methods, and has applied them to solve various decision-making and clustering analysis problems (Wei, 2016, 2018; Wang et al., 2018, 2019a, 2019b, 2020; Wei \& Gao, 2018; Wei et al. 2018; Tian \& Peng, 2020; Tian et al., 2019, 2020; Zhang et al. 2018, 2019a, 2019b).

Definition 1 (Cuong \& Kreinovich, 2013). A PFS $\psi$ in $X$ is defined as $\psi=\left\{\left(x, \mu_{\psi}(x)\right.\right.$, $\left.\left.\eta_{\psi}(x), v_{\psi}(x)\right) \mid x \in X\right\} . \mu_{\psi}(x) \in[0,1]$ represents the positive membership degree of $\psi$, $\eta_{\psi}(x) \in[0,1]$ represents the neutral membership degree of $\psi$ and $v_{\psi}(x) \in[0,1]$ represents 
the negative membership degree of $\psi$, and $\mu_{\psi}(x), \eta_{\psi}(x)$ and $v_{\psi}(x)$ satisfy the following condition: $0 \leq \mu_{\psi}(x)+\eta_{\psi}(x)+v_{\psi}(x) \leq 1$. Then for any $x \in X, \pi_{\psi}(x)=1-\left(\mu_{\psi}(x)+\eta_{\psi}(x)+\right.$ $\left.v_{\psi}(x)\right)$ denotes the refusal membership degree. Particularly, if there is only one element in $X$, then $\psi$ is a PFN, i.e., $\psi=\left(\mu_{\psi}, \eta_{\psi}, v_{\psi}\right)$.

Definition 2 (Ju et al., 2019). Let $\psi, \psi_{1}$ and $\psi_{2}$ be three PFNs and $\lambda>0$, then

(1) $\psi_{1} \otimes \psi_{2}=\left(\left(1-\mu_{\psi_{1}}-\eta_{\psi_{1}}\right)\left(1-\mu_{\psi_{2}}-\eta_{\psi_{2}}\right)-\left(1-\mu_{\psi_{1}}-\eta_{\psi_{1}}-v_{\psi_{1}}\right)\left(1-\mu_{\psi_{2}}-\eta_{\psi_{2}}-v_{\psi_{2}}\right)\right.$, $\left.\left(1-v_{\psi_{1}}\right)\left(1-v_{\psi_{2}}\right)-\left(1-\eta_{\psi_{1}}-v_{\psi_{1}}\right)\left(1-\eta_{\psi_{2}}-v_{\psi_{2}}\right), 1-\left(1-v_{\psi_{1}}\right)\left(1-v_{\psi_{2}}\right)\right) ;$

(2) $\psi^{\lambda}=\left(\left(1-\eta_{\psi}-v_{\psi}\right)^{\lambda}-\left(1-\mu_{\psi}-\eta_{\psi}-v_{\psi}\right)^{\lambda},\left(1-v_{\psi}\right)^{\lambda}-\left(1-\eta_{\psi}-v_{\psi}\right), 1-\left(1-v_{\psi}\right)^{\lambda}\right)$;

(3) $\psi^{c}=\left(v_{\psi}, \eta_{\psi}, \mu_{\psi}\right)$.

Definition 3 (Ju et al., 2019). Let $\psi_{i}=\left\langle\mu_{\psi_{i}}, \eta_{\psi_{i}}, v_{\psi_{i}}\right\rangle(i=1,2, \ldots, n)$ be a group of PFNs, and $w=\left(w_{1}, w_{2}, \ldots, w_{n}\right)^{T}$ be the corresponding weight with $w_{i} \in[0,1]$ and $\sum_{i=1}^{n} w_{i}=1$. Then the picture fuzzy weighted interaction geometric (PFWIG) operator can be defined as:

$$
\begin{aligned}
\operatorname{PFWIG}\left(\psi_{1}, \psi_{2}, \ldots, \psi_{n}\right)= & \left\langle\prod_{i=1}^{n}\left(1-v_{\psi_{i}}-\eta_{\psi_{i}}\right)^{w_{i}}-\prod_{i=1}^{n}\left(1-\mu_{\psi_{i}}-\eta_{\psi_{i}}-v_{\psi_{i}}\right)^{w_{i}},\right. \\
& \left.\prod_{i=1}^{n}\left(1-v_{\psi_{i}}\right)^{w_{i}}-\prod_{i=1}^{n}\left(1-\eta_{\psi_{i}}-v_{\psi_{i}}\right)^{w_{i}}, 1-\prod_{i=1}^{n}\left(1-v_{\psi_{i}}\right)^{w_{i}}\right\rangle .
\end{aligned}
$$

Definition 4 (Wang et al., 2018). Let $\psi_{1}$ and $\psi_{2}$ be two PFNs, then the normalized picture fuzzy Euclidean distance between $\psi_{1}$ and $\psi_{2}$ can be defined as:

$$
d_{E}\left(\begin{array}{ll}
1,2
\end{array}\right) \sqrt{\frac{1}{2}\left(\left(\psi_{1}=\psi_{2}\right)^{2}\left(\begin{array}{ll}
\psi_{1} & \psi_{2}
\end{array}\right)^{2}\left(\begin{array}{ll}
\psi_{1} & \psi_{2}
\end{array}\right)^{2}\left(\begin{array}{ll}
\psi_{1} & \psi_{2}
\end{array}\right)^{2}\right)} .
$$

\subsection{The picture fuzzy exponential entropy}

The information fuzzy entropy, which was defined by Shannon (1948), is a very important concept for MCDM problems. It can measure the amount of information and reflect the size of the uncertainty involved in an event. Then based on the fuzzy entropy, a new entropy measure of PFNs, i.e., the picture fuzzy exponential entropy, is defined as follows.

Definition 5. Let $M: \operatorname{PFSs}(X) \rightarrow[0,1] . M$ is a picture fuzzy entropy iff it satisfies the following axiomatic:

P1. $M(\psi)=0(\min )$ if $\mu_{\psi}=1, \eta_{\psi}=v_{\psi}=0$ or $\mu_{\psi}=0, \eta_{\psi}+v_{\psi}=1$;

P2. $M(\psi)=1$ if $\mu_{\psi}=\eta_{\psi}+v_{\psi}$;

P3. $M\left(\psi_{1}\right) \leq M\left(\psi_{2}\right)$ if $\psi_{1} \leq \psi_{2}$, i.e., $\mu_{\psi_{1}} \leq \mu_{\psi_{2}}, \eta_{\psi_{1}}+v_{\psi_{1}} \geq \eta_{\psi_{2}}+v_{\psi_{2}}$ and $\mu_{\psi_{2}} \leq \eta_{\psi_{2}}+v_{\psi_{2}}$ or $\mu_{\psi_{1}} \geq \mu_{\psi_{2}}, \eta_{\psi_{1}}+v_{\psi_{1}} \leq \eta_{\psi_{2}}+v_{\psi_{2}}$ and $\mu_{\psi_{2}} \geq \eta_{\psi_{2}}+v_{\psi_{2}}$;

P4. $M(\psi)=M\left(\psi^{c}\right)$, here $\psi^{c}$ is the complement set of $\psi$. 
Definition 6. Let $\psi$ be a PFN, the picture fuzzy exponential entropy $M_{e}(\psi)$ can be defined as:

$$
M_{e}(\psi)=\frac{1}{\sqrt{e}(\sqrt{e}-1)}\left(e-\frac{\mu_{\psi}+1-\eta_{\psi}-v_{\psi}}{2} e^{\frac{\mu_{\psi}+1-\eta_{\psi}-v_{\psi}}{2}}-\frac{\eta_{\psi}+v_{\psi}+1-\mu_{\psi}}{2} e^{\frac{\eta_{\psi}+v_{\psi}+1-\mu_{\psi}}{2}}\right) \text {. }
$$

Theorem 1. The picture fuzzy exponential entropy $M_{e}(\psi)$ satisfies the four axiomatic of the picture fuzzy entropy.

Proof. P1. Assume $\frac{\mu_{\psi}+1-\eta_{\psi}-v_{\psi}}{2}=\tau_{\psi}$, then we have $M_{e}(\psi)=\frac{1}{\sqrt{e}(\sqrt{e}-1)}\left[e-\tau_{\psi} e^{\tau_{\psi}}-\right.$ $\left.\left(1-\tau_{\psi}\right) e^{1-\tau_{\psi}}\right]$. Then $M_{e}(\psi)=0$ iff $\tau_{\psi}=1$ or $\tau_{\psi}=0$. Thus, $\frac{\mu_{\psi}+1-\eta_{\psi}-v_{\psi}}{2}=1$ or $\frac{\mu_{\psi}+1-\eta_{\psi}-v_{\psi}}{2}=0$ i.e., $\mu_{\psi}-\eta_{\psi}-v_{\psi}=1$ or $\eta_{\psi}+v_{\psi}-\mu_{\psi}=1$. Since $\mu_{\psi}+\eta_{\psi}+v_{\psi} \leq 1$, then we have $\mu_{\psi}=1$ and $\eta_{\psi}=v_{\psi}=0$ or $\mu_{\psi}=0$ and $\eta_{\psi}+v_{\psi}=1$.

P2. Based on the proof of P1, we can obtain $M_{e}(\psi)=f\left(\tau_{\psi}\right)$, here $f\left(\tau_{\psi}\right)=\frac{1}{\sqrt{e}(\sqrt{e}-1)}[e-$ $\left.\tau_{\psi} e^{\tau_{\psi}}-\left(1-\tau_{\psi}\right) e^{1-\tau_{\psi}}\right]$. In order to prove that Eq. (3) satisfies the condition P2, it is necessary to prove function $f(\mathrm{~K})=\frac{1}{\sqrt{e}(\sqrt{e}-1)}\left[e-\mathrm{K} e^{\mathrm{K}}-(1-\mathrm{K}) e^{1-\mathrm{K}}\right]$ satisfies the condition P2. Where $\mathrm{K}=\tau_{\psi}=\frac{\mu_{\psi}+1-\eta_{\psi}-v_{\psi}}{2}$ and $0 \leq \mathrm{K} \leq 1$. Taking derivatives of $f(\mathrm{~K})$ with respect to $\mathrm{K}$, then we have $f^{\prime}(\mathrm{K})=\frac{1}{\sqrt{e}(\sqrt{e}-1)}\left\{[1+(1-\mathrm{K})] e^{1-\mathrm{K}}-(1+\mathrm{K}) e^{\mathrm{K}}\right\}$. Since $f(x)=(1+x) e^{x}$ is a bijective function and $\left.f^{\prime \prime}(\mathrm{K})\right|_{\mathrm{K}=0.5}<0$, so the function $f(\mathrm{~K})$ has a global maximum value at $\mathrm{K}=0.5$. Then $f\left(\tau_{\psi}\right)$ has a global maximum value at $\tau_{\psi}=0.5$, i.e. , $\mu_{\psi}=\eta_{\psi}+v_{\psi}$. Thus, $\left.M_{e}(\psi)\right|_{\max }=\left.f\left(\tau_{\psi}\right)\right|_{\tau_{\psi}=0.5}=1$.

P3. According to the proof of $\mathrm{P} 2$, we can obtain three results about $f^{\prime}(\mathrm{K})$ : (1) if $0 \leq \mathrm{K}<0.5$, then $f^{\prime}(\mathrm{K})>0$, i.e., $f(\mathrm{~K})$ is an increasing function with respect to $\mathrm{K}$; (2) if $\mathrm{K}=0.5$, then $f^{\prime}(\mathrm{K})=0$; and (3) if $0.5<\mathrm{K} \leq 1$, then $f^{\prime}(\mathrm{K})<0$, i.e., $f(\mathrm{~K})$ is a decreasing function with respect to $K$. Since $\psi_{1} \leq \psi_{2}$, then we have $\mu_{\psi_{1}} \leq \mu_{\psi_{2}} \leq \eta_{\psi_{2}}+v_{\psi_{2}} \leq \eta_{\psi_{1}}+v_{\psi_{1}}$ or $\mu_{\psi_{1}} \geq \mu_{\psi_{2}} \geq \eta_{\psi_{2}}+v_{\psi_{2}} \geq \eta_{\psi_{1}}+v_{\psi_{1}}$. Take $\frac{\mu_{\psi_{1}}+1-\eta_{\psi_{1}}-v_{\psi_{1}}}{2}=\mathrm{K}$ and $\frac{\mu_{\psi_{2}}+1-\eta_{\psi_{2}}-v_{\psi_{2}}}{2}=\mathrm{T}$. If $\mu_{\psi_{1}} \leq \mu_{\psi_{2}} \leq \eta_{\psi_{2}}+v_{\psi_{2}} \leq \eta_{\psi_{1}}+v_{\psi_{1}}$, then we have $\mathrm{K} \leq \mathrm{T} \leq 0.5$, i.e., $f(\mathrm{~K}) \leq f(\mathrm{~T})$. Thus, $f\left(\tau_{\psi_{1}}\right) \leq f\left(\tau_{\psi_{2}}\right)$, i.e., $M_{e}\left(\psi_{1}\right) \leq M_{e}\left(\psi_{2}\right)$ whenever $\psi_{1} \leq \psi_{2}$. Similarly, if $\mu_{\psi_{1}} \geq \mu_{\psi_{2}} \geq$ $\eta_{\psi_{2}}+v_{\psi_{2}} \geq \eta_{\psi_{1}}+v_{\psi_{1}}$, then $f\left(\tau_{\psi_{1}}\right) \leq f\left(\tau_{\psi_{2}}\right)$ can be obtained, i.e., $M_{e}\left(\psi_{1}\right) \leq M_{e}\left(\psi_{2}\right)$ whenever $\psi_{1} \leq \psi_{2}$.

P4. Since $\psi^{c}=\left(v_{\psi}, \eta_{\psi}, \mu_{\psi}\right)$, i.e., $\mu_{\psi}^{c}=v_{\psi}, \eta_{\psi}^{c}=\eta_{\psi}$ and $v_{\psi}^{c}=\mu_{\psi}$. Thus, $M_{e}(\psi)=M_{e}\left(\psi^{c}\right)$ can be obtained. 


\section{The methodology}

Assume there are $n$ sustainable suppliers denoted by $\psi=\left\{\psi_{1}, \psi_{2}, \ldots, \psi_{n}\right\}, m$ criteria denoted by $C=\left\{c_{1}, c_{2}, \ldots, c_{m}\right\}$, and $l$ experts denoted by $\kappa=\left(\kappa_{1}, \kappa_{2}, \ldots, \kappa_{l}\right)$ and the weights of the experts are denoted by $w=\left(w_{1}, w_{2}, \ldots, w_{l}\right)$ satisfying $\sum_{k=1}^{l} w_{k}=1$. The importance of the criteria for the evaluation of a sustainable supplier is $\varpi_{j}$, which is completely unknown. Let $R=\left(\psi_{i j}^{k}\right)_{n \times m}(i=1,2, \ldots, n ; j=1,2, \ldots, m ; k=1,2, \ldots, l)$ be the decision matrix provided by the candidate sustainable suppliers and the $k$-th expert, and $\psi_{i j}^{k}$ be the evaluation value of $\psi_{i}$ for criterion $c_{j}$ being in the form of PFNs. The procedure to rank and select the most desirable sustainable supplier is provided in the following steps and the chart of the proposed framework is shown in Figure 1.

\section{Step 1. Construct the decision matrix}

In the process of SSS, a decision matrix can be constructed by candidate sustainable suppliers and experts simultaneously. Some criteria, which can be measured by an actual numerical value, can be provided by candidate sustainable suppliers directly and the decision-making matrix denoted as $R_{1}=\left(e_{i j}\right)_{n \times x}(i=1,2, \ldots, n ; j=1,2, \ldots, x)$; while other criteria can be evaluated by experts in the form of linguistic terms, as shown in Table 2, and the corresponding decision matrix denoted as $R_{2}^{k}=\left(d_{i j}^{k}\right)_{n \times y}(i=1,2, \ldots, n ; j=1,2, \ldots, y ; k=1,2, \ldots, l, x+y=m)$.

Table 2. The picture fuzzy linguistic and numerical scale

\begin{tabular}{|l|c|c|}
\hline \multicolumn{1}{|c|}{ Linguistic Term } & Numerical terms & PFN \\
\hline Very very high (VVH) & $0.91-1$ & $(1,0,0)$ \\
\hline Very high (VH) & $0.81-090$ & $(0.9,0,0.1)$ \\
\hline High (H) & $0.71-0.80$ & $(0.7,0,0.1)$ \\
\hline Medium high (MH) & $0.61-0.70$ & $(0.5,0.1,0.1)$ \\
\hline Medium (M) & $0.51-0.60$ & $(0.5,0.2,0.2)$ \\
\hline Medium poor (MP) & $0.41-0.50$ & $(0.3,0.3,0.3)$ \\
\hline Poor (P) & $0.31-0.40$ & $(0.1,0.4,0.4)$ \\
\hline Very Poor (VP) & $0.01-0.30$ & $(0,0,1)$ \\
\hline Very very Poor (VVP) & 0 &
\end{tabular}

\section{Step 2. Normalize and translate the decision matrix}

Since the criteria of SSS are generally divided into two types, benefit and cost, the larger the benefit criterion, the smaller the cost criterion. Moreover, the measurements of the criteria, which are denoted by numerical values, are different. Therefore, in order to ensure the comparability of all criteria, the criteria with numerical values need to be normalized by the following formula: 


$$
\bar{e}_{i j}=\left\{\begin{array}{l}
\frac{e_{i j}-\min _{i} e_{i j}}{\max _{i} e_{i j}-\min _{i} e_{i j}}, \text { for benefit criterion } \\
\frac{\max _{i} e_{i j}-e_{i j}}{\max _{i} e_{i j}-\min _{i} e_{i j}}, \text { for cost criterion }
\end{array} .\right.
$$

Then $\bar{R}_{1}=\left(\bar{e}_{i j}\right)_{n \times x}$ and $\bar{e}_{i j} \in[0,1]$. Furthermore, for the other criteria, the evaluation values can be obtained by experts based on the linguistic terms in Table 2. Then all linguistic terms can be translated to PFNs. Moreover, the three membership degrees of PFNs are all in the interval $[0,1]$. So there is no need to normalize the criteria evaluated by experts and $\bar{R}_{2}^{k}=\left(\bar{d}_{i j}^{k}\right)_{n \times y}=\left(d_{i j}^{k}\right)_{n \times y}$. Then based on the decision-making matrix $\bar{R}_{1}=\left(\bar{e}_{i j}\right)_{n \times x}$ and $\bar{R}_{2}^{k}=\left(d_{i j}^{k}\right)_{n \times y}$, the overall translated picture fuzzy decision matrix $\bar{R}^{\prime}=\left(\phi_{i j}^{1}\right)_{n \times x}$ $(i=1,2, \ldots, n ; j=1,2, \ldots, x)$ and $R^{k}=\left(\psi_{i j}^{k}\right)_{n \times y}(i=1,2, \ldots, n ; j=1,2, \ldots, y ; k=1,2, \ldots, l ; x+y=m)$ can be obtained.

\section{Step 3. Aggregate the group of DMs' preferences}

Since the actual data provided by the supplier will not change, it is only necessary to aggregate the evaluation information provided by the experts. According to the aggregation operator, i.e., Eq. (1), the aggregated decision-making preference information of three experts $\bar{R}^{\prime \prime}=\left(\phi_{i j}^{2}\right)_{n \times y}$ can be obtained as:

$$
\begin{aligned}
\phi_{i j}= & \left\langle\prod_{k=1}^{l}\left(1-v_{\psi_{i j}^{k}}-\eta_{\psi_{i j}^{k}}\right)^{w_{k}}-\prod_{k=1}^{l}\left(1-\mu_{\psi_{i j}^{k}}-\eta_{\psi_{i j}^{k}}-v_{\psi_{i j}^{k}}\right)^{w_{k}},\right. \\
& \left.\prod_{k=1}^{l}\left(1-v_{\psi_{i j}^{k}}\right)^{w_{k}}-\prod_{k=1}^{l}\left(1-\eta_{\psi_{i j}^{k}}-v_{\psi_{i j}^{k}}\right)^{w_{k}}, 1-\prod_{k=1}^{l}\left(1-v_{\psi_{i j}^{k}}\right)^{w_{k}}\right\rangle .
\end{aligned}
$$

where $i=1,2, \ldots, n ; j=1,2, \ldots, y ; k=1,2, \ldots, l ; x+y=m$, and $w_{k}$ represents the weight of the $k$-th expert.

\section{Step 4. Calculate the picture fuzzy exponential entropy}

According to the translated picture fuzzy decision matrix $\bar{R}^{\prime}=\left(\phi_{i j}^{1}\right)_{n \times x}$, the aggregated decision-making preference information of three experts $\bar{R}^{\prime \prime}=\left(\phi_{i j}^{2}\right)_{n \times y}$ and the picture fuzzy exponential entropy defined in Def. 6 , the corresponding exponential entropy $\xi_{j}$ on each criterion $c_{j}$ of the aggregated decision-making preference information can be obtained by using the following expression:

$\xi_{j}=\frac{1}{\sqrt{e}(\sqrt{e}-1)}\left(e-\frac{\mu_{\phi_{i j}}+1-\eta_{\phi_{i j}}-v_{\phi_{i j}}}{2} e^{\frac{\mu_{\phi_{i j}}+1-\eta_{\phi_{i j}}-v_{\phi_{i j}}}{2}}-\frac{\eta_{\phi_{i j}}+v_{\phi_{i j}}+1-\mu_{\phi_{i j}}}{2} e^{\frac{\eta_{\phi_{i j}}+v_{\phi_{i j}}+1-\mu_{\phi_{i j}}}{2}}\right)$,

where $i=1,2, \ldots, n$ and $j=1,2, \ldots, m$. 
Step 5. Calculate the weights of the SSS's criteria

Since the information about the weights of the SSS's criteria is completely unknown, the corresponding weights should be determined in advance. Moreover, the picture fuzzy exponential entropy is used to describe the degree of fuzziness and intuitionism. The larger the value of the picture fuzzy exponential entropy, the higher the ambiguity in the judgment of decision-making, and the smaller the weight that should be determined; In contrast, the smaller the picture fuzzy exponential entropy value, the greater the weight that should be provided. Thus, the corresponding picture fuzzy exponential entropy-based weight $\varpi_{j}$ of the criterion can be determined as:

where $\varpi_{j} \in[0,1]$ and $\sum_{j=1}^{m} \varpi_{j}=1$.

$$
\varpi_{j}=\frac{1-\xi_{j}}{m-\sum_{j=1}^{m} \xi_{j}}, j=1,2, \ldots, m,
$$

\section{Step 6. Determine the positive and negative ideal solution respectively}

Since all the criteria are translated into the maximizing type in Step 2, the positive ideal solution $\phi^{+}$and negative ideal solution $\phi^{-}$of each column can be determined as $\phi^{+}=\left\langle\mu^{+}, \eta^{+}, v^{+}\right\rangle$ and $\phi^{-}=\left\langle\mu^{-}, \eta^{-}, v^{-}\right\rangle$respectively.

\section{Step 7. Calculate the separation measure}

The separation between PFNs can be measured using different distances. Based on Steps 3 and 6 , the separation between each aggregated decision-making value $\phi_{i j}$ and the positive ideal solution $\phi^{+}$and negative ideal solution $\phi^{-}$can be calculated by utilizing the normalized picture fuzzy Euclidean distance as:

$$
\begin{aligned}
& \sigma_{i j}^{+}=\sqrt{\frac{1}{2}\left(\left(\mu_{\phi_{i j}}-\mu^{+}\right)^{2}+\left(\eta_{\phi_{i j}}-\eta^{+}\right)^{2}+\left(v_{\phi_{i j}}-v^{+}\right)^{2}+\left(\pi_{\phi_{i j}}-\pi^{+}\right)^{2}\right)} ; \\
& \sigma_{i j}^{-}=\sqrt{\frac{1}{2}\left(\left(\mu_{\phi_{i j}}-\mu^{-}\right)^{2}+\left(\eta_{\phi_{i j}}-\eta^{-}\right)^{2}+\left(v_{\phi_{i j}}-v^{-}\right)^{2}+\left(\pi_{\phi_{i j}}-\pi^{-}\right)^{2}\right)} .
\end{aligned}
$$

\section{Step 8. Calculate the grey relational coefficients}

To overcome the shortcomings of the VIKOR method in data mining, the grey correlation coefficient is combined with the VIKOR method to improve the accuracy of the decisionmaking. Based on Step 7, the positive grey relational coefficient $\varepsilon_{i j}^{+}$and negative grey relational coefficient $\varepsilon_{i j}^{-}$of each aggregated decision-making value $\phi_{i j}$ can be calculated as:

$$
\begin{aligned}
\varepsilon_{i j}^{+} & =\frac{\min _{i} \min _{j} \sigma_{i j}^{+}+\rho \max _{i} \max _{j} \sigma_{i j}^{+}}{\sigma_{i j}^{+}+\rho \max _{i} \max _{j} \sigma_{i j}^{+}} ; \\
\varepsilon_{i j}^{-} & =\frac{\min _{i} \min _{j} \sigma_{i j}^{-}+\rho \max _{i} \max _{j} \sigma_{i j}^{-}}{\sigma_{i j}^{-}+\rho \max _{i} \max _{j} \sigma_{i j}^{-}},
\end{aligned}
$$


where, $\rho$ is the distinguishing coefficient with $\rho \in[0,1]$, and $\rho$ is determined as 0.5 in this paper.

\section{Step 9. Calculate the group utility and individual regret respectively}

According to the VIKOR method and grey relational coefficients $\varepsilon_{i j}^{+}$and $\varepsilon_{i j}^{-}$in Step 8, the picture fuzzy group utility measurement of $S_{i}$ can be obtained as follows:

$$
S_{i}=\sum_{j=1}^{m} \varpi_{j} \frac{\max _{i} \varepsilon_{i j}^{+}-\varepsilon_{i j}^{+}}{\max _{i} \varepsilon_{i j}^{+}-\min _{i} \varepsilon_{i j}^{-}},
$$

and the individual regret $R_{i}$ can be obtained as follows:

$$
R_{i}=\max _{j}\left\{\varpi_{j} \frac{\max _{i} \varepsilon_{i j}^{+}-\varepsilon_{i j}^{+}}{\max _{i} \varepsilon_{i j}^{+}-\min _{i} \varepsilon_{i j}^{-}}\right\} .
$$

Step 10. Calculate the compromise measure

From the group utility measurement $S_{i}$ and individual regret $R_{i}$, the picture fuzzy compromise measure can be determined:

$$
Q_{i}=\vartheta \frac{S_{i}-S^{+}}{S^{-}-S^{+}}+(1-\vartheta) \frac{R_{i}-R^{+}}{R^{-}-R^{+}},
$$

where $S^{+}=\min _{i}\left\{S_{i}\right\}, S^{-}=\max _{i}\left\{S_{i}\right\}, R^{+}=\min _{i}\left\{R_{i}\right\}, R^{-}=\max _{i}\left\{R_{i}\right\}$, and $\vartheta$ represents the maximum overall utility, while $(1-\vartheta)$ is used to weigh the individual regret. In order to maximize the group utility and minimize the individual regret, a balanced value, i.e., $\vartheta=$ 0.5 , is determined.

\section{Step 11. Rank the candidate suppliers}

Based on Step 10, the values of $S_{i}, R_{i}$ and $Q_{i}(i=1,2, \ldots, n)$ can be sorted in ascending order. Then the optimal sustainable supplier can be determined and satisfy the following conditions.

Condition 1: Acceptable advantage

$$
Q\left(\psi^{(2)}\right)-Q\left(\psi^{(1)}\right) \geq \frac{1}{n-1}
$$

where $\psi^{(1)}$ denotes the optimal sustainable supplier with the first position; while $\psi^{(2)}$ denotes the sub-optimal sustainable supplier with the second position.

Condition 2: Acceptable stability

Candidate supplier $\psi^{(1)}$ should also be superior in $S_{i}$ or $R_{i}$.

If condition one cannot be satisfied, then the maximum value of $n$ can be determined as:

$$
Q\left(\psi^{(i)}\right)-Q\left(\psi^{(1)}\right) \leq \frac{1}{n-1} .
$$

Then all the alternatives $\psi^{(i)}(i=1,2, \ldots, n)$ are the compromise solutions.

If condition two cannot be satisfied, then both the candidate suppliers $\psi^{(1)}$ and $\psi^{(2)}$ are the compromise solutions. 


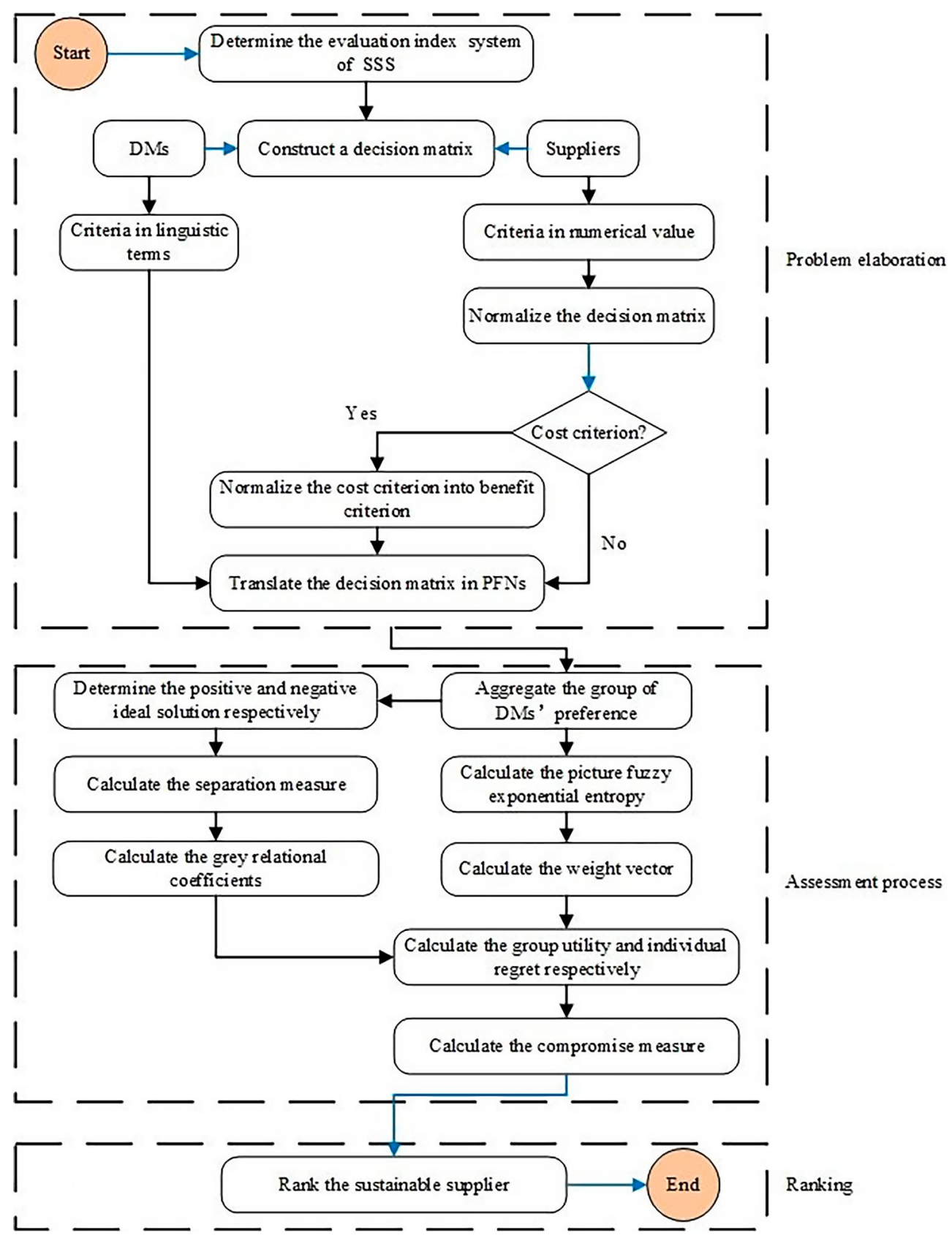

Figure 1. The chart of proposed MCDM framework for SSS 


\section{The experiment and results}

In this section, the performance of the proposed MCDM framework can be demonstrated by applying it to a chemical manufacturing enterprise, i.e., $\mathrm{AB}$, in China. The $\mathrm{AB}$ enterprise is mainly engaged in the manufacturing of chemical products and equipment. In recent years, local residents have complained about pollution from $\mathrm{AB}$. The $\mathrm{AB}$ enterprise has also been warned by the government about environmental pollution. Consequently, it had to create a sustainable development department for its long-term survival. Moreover, SSS plays a key role in sustainable development. The proposed MCDM framework in this paper can help the $\mathrm{AB}$ enterprise select a suitable sustainable supplier.

According to the evaluation criteria of SSS presented in Table 1, the evaluation process involves three criteria, economic, environmental and social, and fourteen sub-criteria. In other words, there are six economic sub-criteria, i.e., $c_{1}, c_{2}, c_{3}, c_{4}, c_{5}$ and $c_{6}$, five environmental sub-criteria, i.e., $c_{7}, c_{8}, c_{9}, c_{10}$ and $c_{11}$, and three social sub-criteria for social, i.e., $c_{12}, c_{13}$ and $c_{14}$. More details can be found in Table 1. Moreover, the weight of the fourteen sub-criteria is completely unknown. Based on an investigation and analysis, ten suppliers $\psi_{i}(i=1,2, \ldots, 10)$, which intend to cooperate with the $\mathrm{AB}$ enterprise, are selected.

Moreover, DMs are composed of suppliers and experts, including the sustainable development strategic department manager, production department manager and purchasing department manager. More details about the experts can be found in Table 3. In the evaluation process, ten suppliers need to provide their actual data for certain criteria, which can be measured by numerical values, while other criteria can be evaluated subjectively by three experts in the form of the linguistic terms presented in Table 2. In order to demonstrate the importance of different experts' opinion, the weights of three experts is determined as $w=(0.4,0.3,0.3)$. The corresponding evaluation steps are now provided.

Table 3. The information of experts

\begin{tabular}{|c|l|l|l|l|c|}
\hline Experts & \multicolumn{1}{|c|}{ Sex } & Education & Technical title & Position & Working years \\
\hline Expert 1 & Male & Ph.D. & Senior Engineer & $\begin{array}{l}\text { Sustainable development } \\
\text { strategic manager }\end{array}$ & 15 \\
\hline Expert 2 & Male & Ph.D. & Senior Engineer & Production department manager & 16 \\
\hline Expert 3 & Female & Ph.D. & Engineer & Purchasing department manager & 13 \\
\hline
\end{tabular}

\subsection{The proposed MCDM framework}

Step 1. Construct the decision matrix. Since criteria $c_{1}, c_{2}, c_{3}, c_{5}, c_{6}, c_{8}$ and $c_{9}$ can be measured by numerical values during the measurement process, the corresponding evaluation information can be provided by candidate sustainable suppliers directly, as shown in Table 4 . Then based on the experts' knowledge and experience, and the development needs of the $\mathrm{AAB}$ enterprise, other criteria, i.e., $c_{4}, c_{7}, c_{10}, c_{11}, c_{12}, c_{13}$ and $c_{14}$ can be evaluated by three experts in the form of linguistic terms, as shown in Table 5. 
Table 4 . The evaluation values provided by ten suppliers.

\begin{tabular}{|c|c|c|c|c|c|c|c|}
\hline$R_{1}$ & $c_{1}$ & $c_{2}$ & $c_{3}$ & $c_{5}$ & $c_{6}$ & $c_{8}$ & $c_{9}$ \\
\hline$\psi_{1}$ & $98 \%$ & 315 & 110 & $95.5 \%$ & $80 \%$ & $47.5 \%$ & 0.2 \\
\hline$\psi_{2}$ & $97 \%$ & 300 & 115 & $97 \%$ & $74.5 \%$ & $53 \%$ & 1.4 \\
\hline$\psi_{3}$ & $94.5 \%$ & 290 & 120 & $97 \%$ & $61 \%$ & $49 \%$ & 1.7 \\
\hline$\psi_{4}$ & $96 \%$ & 300 & 110 & $96 \%$ & $71.5 \%$ & $60 \%$ & 1.9 \\
\hline$\psi_{5}$ & $98 \%$ & 310 & 109 & $93.5 \%$ & $66 \%$ & $49 \%$ & 0.3 \\
\hline$\psi_{6}$ & $94 \%$ & 305 & 120 & $94.5 \%$ & $53 \%$ & $40 \%$ & 1.6 \\
\hline$\psi_{7}$ & $95.5 \%$ & 285 & 117 & $95 \%$ & $55 \%$ & $51.5 \%$ & 1.2 \\
\hline$\psi_{8}$ & $99 \%$ & 330 & 104 & $90 \%$ & $77.5 \%$ & $66 \%$ & 0 \\
\hline$\psi_{9}$ & $96 \%$ & 295 & 103 & $96 \%$ & $70 \%$ & $49.5 \%$ & 0.7 \\
\hline$\psi_{10}$ & $98 \%$ & 280 & 130 & $98 \%$ & $85 \%$ & $42 \%$ & 1.5 \\
\hline
\end{tabular}

Table 5. The evaluation values provided by experts

\begin{tabular}{|c|c|c|c|c|c|c|c|}
\hline$R_{2}^{1}$ & $c_{4}$ & $c_{7}$ & $c_{10}$ & $c_{11}$ & $c_{12}$ & $c_{13}$ & $c_{14}$ \\
\hline$\psi_{1}$ & $\mathrm{VVH}$ & $\mathrm{VH}$ & $\mathrm{P}$ & $\mathrm{VH}$ & $\mathrm{H}$ & $\mathrm{VVP}$ & $\mathrm{H}$ \\
\hline$\psi_{2}$ & $\mathrm{M}$ & $\mathrm{M}$ & $\mathrm{P}$ & $\mathrm{H}$ & $\mathrm{MH}$ & $\mathrm{H}$ & $\mathrm{VH}$ \\
\hline$\psi_{3}$ & $\mathrm{VH}$ & $\mathrm{H}$ & $\mathrm{VH}$ & $\mathrm{M}$ & $\mathrm{M}$ & $\mathrm{H}$ & $\mathrm{P}$ \\
\hline$\psi_{4}$ & $\mathrm{VVH}$ & $\mathrm{MH}$ & $\mathrm{H}$ & $\mathrm{VH}$ & $\mathrm{VH}$ & $\mathrm{MH}$ & $\mathrm{VH}$ \\
\hline$\psi_{5}$ & $\mathrm{P}$ & $\mathrm{VP}$ & $\mathrm{MP}$ & $\mathrm{P}$ & $\mathrm{MP}$ & $\mathrm{H}$ & $\mathrm{MH}$ \\
\hline$\psi_{6}$ & $\mathrm{VH}$ & $\mathrm{H}$ & $\mathrm{MH}$ & $\mathrm{M}$ & $\mathrm{VH}$ & $\mathrm{MH}$ & $\mathrm{MP}$ \\
\hline$\psi_{7}$ & $\mathrm{MP}$ & $\mathrm{MP}$ & $\mathrm{H}$ & $\mathrm{VH}$ & $\mathrm{H}$ & $\mathrm{H}$ & $\mathrm{VH}$ \\
\hline$\psi_{8}$ & $\mathrm{VP}$ & $\mathrm{VP}$ & $\mathrm{P}$ & $\mathrm{VP}$ & $\mathrm{MP}$ & $\mathrm{VP}$ & $\mathrm{VP}$ \\
\hline$\psi_{9}$ & $\mathrm{MP}$ & $\mathrm{MH}$ & $\mathrm{MP}$ & $\mathrm{H}$ & $\mathrm{MP}$ & $\mathrm{MH}$ & $\mathrm{H}$ \\
\hline$\psi_{10}$ & $\mathrm{M}$ & $\mathrm{MP}$ & $\mathrm{MP}$ & $\mathrm{M}$ & $\mathrm{H}$ & $\mathrm{MH}$ & $\mathrm{H}$ \\
\hline$R_{2}^{2}$ & $c_{4}$ & $c_{7}$ & $c_{10}$ & $c_{11}$ & $c_{12}$ & $c_{13}$ & $c_{14}$ \\
\hline$\psi_{1}$ & $\mathrm{H}$ & $\mathrm{MH}$ & $\mathrm{MH}$ & $\mathrm{VVH}$ & $\mathrm{H}$ & $\mathrm{H}$ & $\mathrm{H}$ \\
\hline$\psi_{2}$ & $\mathrm{M}$ & $\mathrm{MH}$ & $\mathrm{H}$ & $\mathrm{H}$ & $\mathrm{MH}$ & $\mathrm{H}$ & $\mathrm{M}$ \\
\hline$\psi_{3}$ & $\mathrm{MH}$ & $\mathrm{H}$ & $\mathrm{M}$ & $\mathrm{H}$ & $\mathrm{H}$ & $\mathrm{H}$ & $\mathrm{H}$ \\
\hline$\psi_{4}$ & $\mathrm{H}$ & $\mathrm{MH}$ & $\mathrm{H}$ & $\mathrm{MH}$ & $\mathrm{MH}$ & $\mathrm{M}$ & $\mathrm{M}$ \\
\hline$\psi_{5}$ & $\mathrm{M}$ & $\mathrm{H}$ & $\mathrm{MH}$ & $\mathrm{H}$ & $\mathrm{H}$ & $\mathrm{MP}$ & $\mathrm{M}$ \\
\hline$\psi_{6}$ & $\mathrm{M}$ & $\mathrm{M}$ & $\mathrm{H}$ & $\mathrm{M}$ & $\mathrm{P}$ & $\mathrm{MP}$ & $\mathrm{P}$ \\
\hline$\psi_{7}$ & $\mathrm{M}$ & $\mathrm{P}$ & $\mathrm{P}$ & $\mathrm{M}$ & $\mathrm{H}$ & $\mathrm{H}$ & $\mathrm{P}$ \\
\hline$\psi_{8}$ & $\mathrm{MH}$ & $\mathrm{MH}$ & $\mathrm{H}$ & $\mathrm{H}$ & $\mathrm{H}$ & $\mathrm{H}$ & $\mathrm{P}$ \\
\hline$\psi_{9}$ & $\mathrm{H}$ & $\mathrm{MH}$ & $\mathrm{H}$ & $\mathrm{MH}$ & $\mathrm{MH}$ & $\mathrm{P}$ & $\mathrm{M}$ \\
\hline$\psi_{10}$ & $\mathrm{M}$ & $\mathrm{M}$ & $\mathrm{M}$ & $\mathrm{M}$ & $\mathrm{H}$ & $\mathrm{P}$ & $\mathrm{M}$ \\
\hline & & & & & & \\
\hline
\end{tabular}


End of Table 5

\begin{tabular}{|c|c|c|c|c|c|c|c|}
\hline$R_{2}^{3}$ & $c_{4}$ & $c_{7}$ & $c_{10}$ & $c_{11}$ & $c_{12}$ & $c_{13}$ & $c_{14}$ \\
\hline$\psi_{1}$ & $\mathrm{VH}$ & $\mathrm{H}$ & $\mathrm{H}$ & $\mathrm{H}$ & $\mathrm{VH}$ & $\mathrm{MP}$ & $\mathrm{VH}$ \\
\hline$\psi_{2}$ & $\mathrm{MH}$ & $\mathrm{M}$ & $\mathrm{MH}$ & $\mathrm{M}$ & $\mathrm{M}$ & $\mathrm{M}$ & $\mathrm{VVH}$ \\
\hline$\psi_{3}$ & $\mathrm{VVH}$ & $\mathrm{VH}$ & $\mathrm{H}$ & $\mathrm{H}$ & $\mathrm{VH}$ & $\mathrm{H}$ & $\mathrm{MH}$ \\
\hline$\psi_{4}$ & $\mathrm{VH}$ & $\mathrm{MH}$ & $\mathrm{M}$ & $\mathrm{VH}$ & $\mathrm{H}$ & $\mathrm{M}$ & $\mathrm{H}$ \\
\hline$\psi_{5}$ & $\mathrm{MP}$ & $\mathrm{P}$ & $\mathrm{VP}$ & $\mathrm{P}$ & $\mathrm{P}$ & $\mathrm{MP}$ & $\mathrm{P}$ \\
\hline$\psi_{6}$ & $\mathrm{VH}$ & $\mathrm{VH}$ & $\mathrm{H}$ & $\mathrm{H}$ & $\mathrm{MH}$ & $\mathrm{MH}$ & $\mathrm{H}$ \\
\hline$\psi_{7}$ & $\mathrm{P}$ & $\mathrm{MP}$ & $\mathrm{MP}$ & $\mathrm{P}$ & $\mathrm{H}$ & $\mathrm{H}$ & $\mathrm{VH}$ \\
\hline$\psi_{8}$ & $\mathrm{MP}$ & $\mathrm{P}$ & $\mathrm{MP}$ & $\mathrm{MH}$ & $\mathrm{H}$ & $\mathrm{H}$ & $\mathrm{H}$ \\
\hline$\psi_{9}$ & $\mathrm{H}$ & $\mathrm{MH}$ & $\mathrm{H}$ & $\mathrm{P}$ & $\mathrm{MP}$ & $\mathrm{MH}$ & $\mathrm{MP}$ \\
\hline$\psi_{10}$ & $\mathrm{MP}$ & $\mathrm{H}$ & $\mathrm{VH}$ & $\mathrm{H}$ & $\mathrm{VH}$ & $\mathrm{MH}$ & $\mathrm{H}$ \\
\hline
\end{tabular}

Step 2. Normalize and translate the decision matrix. Since the measurement of the criteria presented in Tables $4-5$ is different, so the criteria evaluated by suppliers should be normalized. Apparently, criteria $c_{1}, c_{3}, c_{5}$ and $c_{8}$ are benefit types, while criteria $c_{2}, c_{6}$ and $c_{9}$ are cost types. Based on Eq. (4), and the picture fuzzy linguistic and numerical scale presented in Table 2, all evaluation information can be translated into PFNs.

Step 3. Aggregate the DMs' preferences. From Eq. (5), the experts' preferences can be aggregated as shown in Table 6.

Table 6. The aggregated picture fuzzy decision matrix of three experts

\begin{tabular}{|c|c|c|c|c|c|c|c|}
\hline $\bar{R}^{\prime \prime}$ & $c_{4}$ & $c_{7}$ & $c_{10}$ & $c_{11}$ & $c_{12}$ & $c_{13}$ & $c_{14}$ \\
\hline$\psi_{1}$ & $(0.94,0,0.06)$ & $(0.83,0.03,0.13)$ & $(0.6,0.18,0.21)$ & $(0.93,0,0.07)$ & $(0.9,0,0.1)$ & $(0,0,1)$ & $(0.9,0,0.1)$ \\
\hline$\Psi_{2}$ & $(0.77,0.1,0.13)$ & $(0.77,0.1,0.13)$ & $(0.6,0.18,0.21)$ & $(0.64,0.03,0.1)$ & $(0.73,0.1,0.17)$ & $(0.64,0.03,0.1)$ & $(0.9,0.3,0.07)$ \\
\hline$\psi_{3}$ & $(0.86,0.04,0.1)$ & $(0.9,0,0.1)$ & $(0.87,0.03,0.1)$ & $(0.62,0.04,0.1)$ & $(0.86,0.04,0.1)$ & $(0.7,0,0.1)$ & $(0.6,0.18,0.21)$ \\
\hline$\psi_{4}$ & $(0.94,0,0.06)$ & $(0.7,0.1,0.2)$ & $(0.64,0.03,0.1)$ & $(0.83,0.03,0.13)$ & $(0.83,0.03,0.13)$ & $(0.76,0.1,0.14)$ & $(0.87,0.03,0.1)$ \\
\hline$\psi_{5}$ & $(0.42,0.23,0.21)$ & $(0.26,0.32,0.29)$ & $(0.45,0.28,0.27)$ & $(0.39,0.24,0.25)$ & $(0.48,0.2,0.2)$ & $(0.57,0.13,0.16)$ & $(0.62,0.18,0.2)$ \\
\hline$\Psi_{6}$ & $(0.87,0.03,0.1)$ & $(0.87,0.03,0.1)$ & $(0.81,0.04,0.14)$ & $(0.56,0.07,0.1)$ & $(0.65,0.15,0.19)$ & $(0.67,0.13,0.2)$ & $(0.48,0.2,0.2)$ \\
\hline$\Psi_{7}$ & $(0.44,0.22,0.20)$ & $(0.43,0.24,0.23)$ & $(0.49,0.18,0.19)$ & $(0.68,0.15,0.17)$ & $(0.7,0,0.1)$ & $(0.7,0,0.1)$ & $(0.71,0.13,0.17)$ \\
\hline$\Psi_{8}$ & $(0.4,0.31,0.29)$ & $(0.36,0.33,0.31)$ & $(0.45,0.21,0.21)$ & $(0.46,0.28,0.26)$ & $(0.61,0.09,0.14)$ & $(0.34,0.27,0.3)$ & $(0.26,0.32,0.29)$ \\
\hline$\psi_{9}$ & $(0.61,0.09,0.14)$ & $(0.7,0.1,0.2)$ & $(0.61,0.09,0.14)$ & $(0.65,0.15,0.19)$ & $(0.63,0.17,0.2)$ & $(0.59,0.18,0.23)$ & $(0.59,0.1,0.13)$ \\
\hline$\Psi_{10}$ & $(0.52,0.13,0.13)$ & $(0.57,0.12,0.14)$ & $(0.74,0.12,0.14)$ & $(0.56,0.07,0.1)$ & $(0.9,0,0.1)$ & $(0.59,0.18,0.23)$ & $(0.64,0.03,0.1)$ \\
\hline
\end{tabular}

Step 4. Calculate the picture fuzzy exponential entropy. From Eq. (6), the corresponding exponential entropy $\xi_{j}$ on each criterion $c_{j}$ can be obtained as presented in Table 7.

Table 7. The picture fuzzy exponential entropy

\begin{tabular}{|c|c|c|c|c|c|c|c|c|c|c|c|c|c|c|}
\hline$c_{j}$ & $c_{1}$ & $c_{2}$ & $c_{3}$ & $c_{4}$ & $c_{5}$ & $c_{6}$ & $c_{7}$ & $c_{8}$ & $c_{9}$ & $c_{10}$ & $c_{11}$ & $c_{12}$ & $c_{13}$ & $c_{14}$ \\
\hline$\xi_{j}$ & 0.57 & 0.61 & 0.59 & 0.69 & 0.56 & 0.55 & 0.75 & 0.64 & 0.46 & 0.84 & 0.78 & 0.69 & 0.75 & 0.75 \\
\hline
\end{tabular}


Step 5. Calculate the weights of the SSS's criteria. From Eq. (7) and Table 7, the weight of the criterion is determined as shown in Table 8.

Table 8 . The weight of the criterion

\begin{tabular}{|c|c|c|c|c|c|c|c|c|c|c|c|c|c|c|}
\hline$c_{j}$ & $c_{1}$ & $c_{2}$ & $c_{3}$ & $c_{4}$ & $c_{5}$ & $c_{6}$ & $c_{7}$ & $c_{8}$ & $c_{9}$ & $c_{10}$ & $c_{11}$ & $c_{12}$ & $c_{13}$ & $c_{14}$ \\
\hline$\varpi_{j}$ & 0.09 & 0.08 & 0.09 & 0.06 & 0.09 & 0.09 & 0.05 & 0.07 & 0.1 & 0.03 & 0.05 & 0.06 & 0.05 & 0.05 \\
\hline
\end{tabular}

Step 6. Determine the positive and negative ideal solution respectively. Based on the definition of PFNs, the picture fuzzy positive ideal solution $\phi^{+}$and negative ideal solution $\phi^{-}$of each column can be determined as $\phi^{+}=\langle 1,0,0\rangle$ and $\phi^{-}=\langle 0,0,1\rangle$ respectively.

Steps 7-8. Calculate the separation measure and the grey relational coefficients respectively. From Eqs (8) and (9), the separation between the aggregated evaluation value $\phi_{i j}$ and the ideal solutions $\phi^{+}$and $\phi^{-}$can be calculated respectively. Then the positive grey relational coefficient $\varepsilon_{i j}^{+}$and negative grey relational coefficient $\varepsilon_{i j}^{-}$of each aggregated evaluation value $\phi_{i j}$ can be calculated.

Steps 9-10. Calculate the group utility, individual regret and compromise measure respectively. From Eqs (12)-(14) and Steps 7-8, the group utility, individual regret and compromise measure can be obtained as presented in Table 9.

Table 9. The group utility, individual regret and compromise measure

\begin{tabular}{|c|c|c|c|c|c|c|c|c|c|c|}
\hline & $\psi_{1}$ & $\psi_{2}$ & $\psi_{3}$ & $\psi_{4}$ & $\psi_{5}$ & $\psi_{6}$ & $\psi_{7}$ & $\psi_{8}$ & $\psi_{9}$ & $\psi_{10}$ \\
\hline$S_{i}$ & 0.51 & 0.54 & 0.47 & 0.54 & 0.63 & 0.6 & 0.6 & 0.61 & 0.56 & 0.5 \\
\hline$R_{i}$ & 0.09 & 0.1 & 0.1 & 0.1 & 0.08 & 0.1 & 0.09 & 0.09 & 0.09 & 0.1 \\
\hline$Q_{i}$ & 0.22 & 0.55 & 0.34 & 0.7 & 0.5 & 0.74 & 0.58 & 0.61 & 0.39 & 0.44 \\
\hline$S$ & 3 & 4 & 1 & 4 & 10 & 7 & 7 & 9 & 6 & 2 \\
\hline$R$ & 2 & 6 & 6 & 10 & 1 & 6 & 2 & 2 & 2 & 6 \\
\hline$Q$ & 1 & 6 & 2 & 9 & 5 & 10 & 7 & 8 & 3 & 4 \\
\hline
\end{tabular}

Step 11. Rank the alternatives. From the results presented in Table 9 and Eq. (15), it can be seen that the first condition is satisfied, i.e., $Q^{(2)}-Q^{(1)}=Q_{3}-Q_{1}=0.34-0.22=0.12>\frac{1}{10-1}$. However, the second condition cannot be satisfied. Thus, $\psi_{1}$ and $\psi_{3}$ are the compromise solutions. In other words, $\psi_{1}$ and $\psi_{3}$ are the most suitable sustainable suppliers and the $\mathrm{AB}$ enterprise can choose $\psi_{1}$ or $\psi_{3}$ based on their preferences and the actual circumstances.

\subsection{A sensitivity analysis}

In this subsection, a sensitivity analysis is conducted to confirm the validity of the proposed framework. A sensitivity analysis can be divided into three cases: (1) if parameter $\vartheta$ is fixed, i.e., $\vartheta=0.5$, then the influence of the different values of parameter $\rho$ in the grey correlation coefficient on the final ranking is discussed; (2) if the parameter $\rho$ is fixed, i.e., $\rho=0.5$, then the influence of the different values of parameter $\vartheta$ in the VIKOR method on the final ranking is discussed; (3) if $\vartheta \in[0,1]$ and $\rho \in[0,1]$, then the influence of the different values of two parameters are discussed. The results are shown in Tables 10-11 and Figures 2-4. 

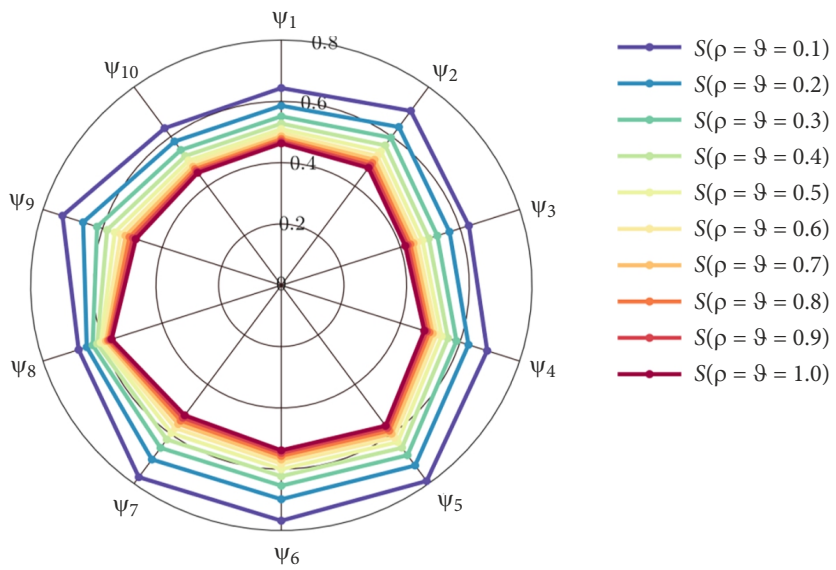

Figure 2. The variation trend of $S_{i}$ with $\vartheta \in[0,1]$ and $\rho \in[0,1]$
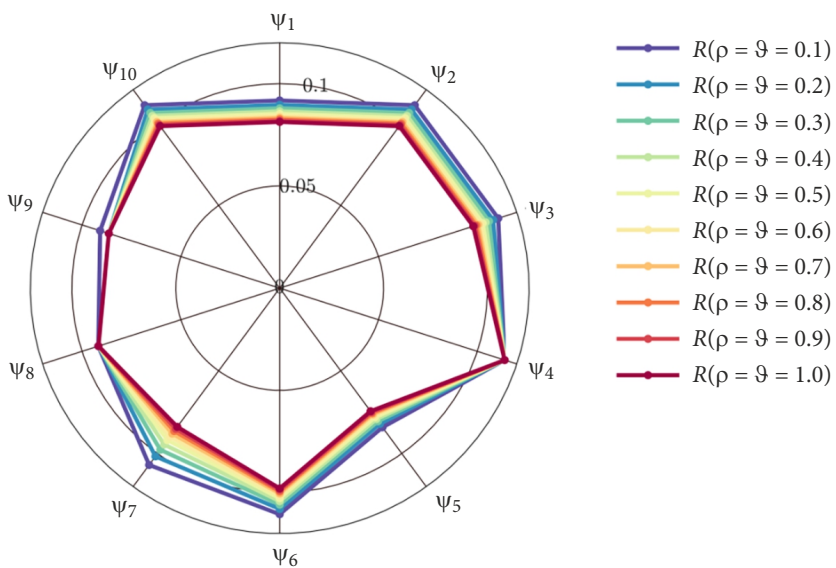

Figure 3. The variation trend of $R_{i}$ with $\vartheta \in[0,1]$ and $\rho \in[0,1]$
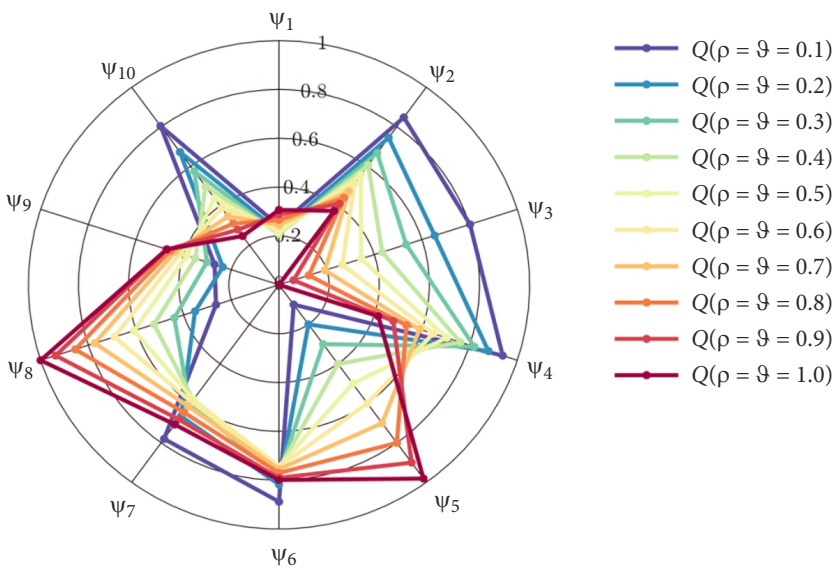

Figure 4. The variation trend of $Q_{i}$ with $\vartheta \in[0,1]$ and $\rho \in[0,1]$ 
(1) The parameter $\vartheta$ is fixed, i.e., $\vartheta=0.5$, and the different values of parameter $\rho$ in the grey correlation coefficient are determined; the final results are shown in Table 10. Apparently, if $\rho=0.1,0.2,0.3,0.4,0.5$, then condition one is satisfied, but condition two is not satisfied, and the $\psi_{1}$ and $\psi_{3}$ are compromise solutions; and if $\rho=0.6,0.7,0.8,0.9,1$, then condition one is not satisfied, but condition two is satisfied, and $\psi_{1}$ and $\psi_{3}$ are also compromise solutions. In other words, the different values of parameter $\rho$ in the grey correlation coefficient cannot influence the final ranking.

(2) The parameter $\rho$ is fixed, i.e., $\rho=0.5$, and the values of parameter $\vartheta$ are changed, the results are presented in Table 11. If $\vartheta=0.1,0.2,0.3$, then condition one is not satisfied and condition two is satisfied, and $\psi_{1}$ and $\psi_{5}$ are compromise solutions; if $\vartheta=0.4$, then $\psi_{1}$ and $\psi_{9}$ are compromise solutions; if $\vartheta=0.5,0.6,0.7,0.8$, then $\psi_{1}$ and $\psi_{3}$ are also compromise solutions; and if $\vartheta=0.9,1$, then $\psi_{3}$ is a compromise solution.

(3) If two parameters $\vartheta$ and $\rho$ change simultaneously, the final results are shown in Figures 2-4. If $\rho=\vartheta=0.1$, then $Q_{5}$ is the optimal solution; if $\rho=\vartheta=0.2,0.3$, then $Q_{1}$ and $Q_{5}$ are compromise solutions; if $\rho=\vartheta=0.4$, then $Q_{1}$ and $Q_{9}$ are compromise solutions; if $\rho=\vartheta=0.5,0.6,0.7$, then $Q_{1}$ and $Q_{3}$ are compromise solutions; and if $\rho=\vartheta=0.8,0.9,1$, then $Q_{3}$ is the optimal solution. Based on Figures 2-4, we can see that the values of $S_{i}$ and $R_{i}$ decrease when the two parameter values increase. In particular, with the larger of two parameters $\vartheta$ and $\rho$, the value of $Q_{1}$ increases gradually, while the value of $Q_{3}$ becomes increasingly smaller, and the corresponding group utility reaches a maximum value.

From the above analysis, it can be seen that the proposed MCDM framework can also obtain the optimal solution or compromise solution for different parameter values.

Table 10. The final results with $\vartheta=0.5$ and $\rho \in[0,1]$

\begin{tabular}{|c|c|c|c|c|c|c|c|c|c|c|c|}
\hline$\vartheta=0.5$ & & $\psi_{1}$ & $\psi_{2}$ & $\psi_{3}$ & $\psi_{4}$ & $\psi_{5}$ & $\psi_{6}$ & $\psi_{7}$ & $\psi_{8}$ & $\psi_{9}$ & $\psi_{10}$ \\
\hline \multirow{3}{*}{$\rho=0.1$} & $S_{i}$ & 0.64 & 0.70 & 0.63 & 0.69 & 0.79 & 0.77 & 0.77 & 0.68 & 0.73 & 0.63 \\
\hline & $R_{i}$ & 0.09 & 0.11 & 0.11 & 0.11 & 0.08 & 0.11 & 0.11 & 0.09 & 0.09 & 0.11 \\
\hline & $Q_{i}$ & 0.17 & 0.68 & 0.45 & 0.69 & 0.50 & 0.88 & 0.83 & 0.29 & 0.44 & 0.46 \\
\hline \multirow{3}{*}{$\rho=0.2$} & $S_{i}$ & 0.59 & 0.64 & 0.56 & 0.63 & 0.73 & 0.70 & 0.70 & 0.65 & 0.67 & 0.58 \\
\hline & $R_{i}$ & 0.09 & 0.11 & 0.11 & 0.11 & 0.08 & 0.11 & 0.10 & 0.09 & 0.09 & 0.11 \\
\hline & $Q_{i}$ & 0.19 & 0.64 & 0.41 & 0.70 & 0.50 & 0.82 & 0.73 & 0.42 & 0.38 & 0.46 \\
\hline \multirow{3}{*}{$\rho=0.3$} & $S_{i}$ & 0.55 & 0.60 & 0.52 & 0.59 & 0.69 & 0.65 & 0.66 & 0.63 & 0.62 & 0.55 \\
\hline & $R_{i}$ & 0.09 & 0.11 & 0.11 & 0.11 & 0.08 & 0.11 & 0.10 & 0.09 & 0.08 & 0.11 \\
\hline & $Q_{i}$ & 0.20 & 0.60 & 0.38 & 0.70 & 0.50 & 0.78 & 0.67 & 0.51 & 0.38 & 0.45 \\
\hline \multirow{3}{*}{$\rho=0.4$} & $S_{i}$ & 0.53 & 0.56 & 0.49 & 0.56 & 0.66 & 0.62 & 0.62 & 0.62 & 0.58 & 0.52 \\
\hline & $R_{i}$ & 0.09 & 0.10 & 0.10 & 0.11 & 0.08 & 0.10 & 0.09 & 0.09 & 0.09 & 0.10 \\
\hline & $Q_{i}$ & 0.21 & 0.58 & 0.36 & 0.70 & 0.50 & 0.76 & 0.62 & 0.56 & 0.39 & 0.44 \\
\hline \multirow{3}{*}{$\rho=0.5$} & $S_{i}$ & 0.51 & 0.54 & 0.47 & 0.54 & 0.63 & 0.60 & 0.60 & 0.61 & 0.56 & 0.50 \\
\hline & $R_{i}$ & 0.09 & 0.10 & 0.10 & 0.11 & 0.08 & 0.10 & 0.09 & 0.09 & 0.09 & 0.10 \\
\hline & $Q_{i}$ & 0.22 & 0.55 & 0.34 & 0.70 & 0.50 & 0.74 & 0.58 & 0.61 & 0.39 & 0.44 \\
\hline
\end{tabular}


End of Table 10

\begin{tabular}{|c|c|c|c|c|c|c|c|c|c|c|c|}
\hline$\vartheta=0.5$ & & $\psi_{1}$ & $\psi_{2}$ & $\psi_{3}$ & $\psi_{4}$ & $\psi_{5}$ & $\psi_{6}$ & $\psi_{7}$ & $\psi_{8}$ & $\psi_{9}$ & $\psi_{10}$ \\
\hline \multirow{3}{*}{$\rho=0.6$} & $S_{i}$ & 0.50 & 0.52 & 0.46 & 0.52 & 0.61 & 0.58 & 0.58 & 0.60 & 0.54 & 0.49 \\
\hline & $R_{i}$ & 0.08 & 0.10 & 0.10 & 0.11 & 0.08 & 0.10 & 0.09 & 0.09 & 0.09 & 0.10 \\
\hline & $Q_{i}$ & 0.22 & 0.54 & 0.33 & 0.71 & 0.50 & 0.73 & 0.55 & 0.64 & 0.39 & 0.43 \\
\hline \multirow{3}{*}{$\rho=0.7$} & $S_{i}$ & 0.49 & 0.51 & 0.44 & 0.51 & 0.60 & 0.57 & 0.56 & 0.59 & 0.52 & 0.48 \\
\hline & $R_{i}$ & 0.08 & 0.10 & 0.10 & 0.11 & 0.08 & 0.10 & 0.09 & 0.09 & 0.09 & 0.10 \\
\hline & $Q_{i}$ & 0.23 & 0.52 & 0.32 & 0.71 & 0.50 & 0.72 & 0.53 & 0.67 & 0.39 & 0.43 \\
\hline \multirow{3}{*}{$\rho=0.8$} & $S_{i}$ & 0.48 & 0.49 & 0.43 & 0.50 & 0.59 & 0.56 & 0.55 & 0.58 & 0.51 & 0.47 \\
\hline & $R_{i}$ & 0.08 & 0.10 & 0.10 & 0.11 & 0.08 & 0.10 & 0.09 & 0.09 & 0.09 & 0.10 \\
\hline & $Q_{i}$ & 0.23 & 0.51 & 0.31 & 0.71 & 0.50 & 0.72 & 0.51 & 0.69 & 0.39 & 0.43 \\
\hline \multirow{3}{*}{$\rho=0.9$} & $S_{i}$ & 0.47 & 0.48 & 0.42 & 0.49 & 0.58 & 0.55 & 0.53 & 0.57 & 0.50 & 0.46 \\
\hline & $R_{i}$ & 0.08 & 0.10 & 0.10 & 0.11 & 0.07 & 0.10 & 0.09 & 0.09 & 0.09 & 0.10 \\
\hline & $Q_{i}$ & 0.24 & 0.50 & 0.30 & 0.71 & 0.50 & 0.71 & 0.49 & 0.71 & 0.39 & 0.43 \\
\hline \multirow{3}{*}{$\rho=1$} & $S_{i}$ & 0.46 & 0.47 & 0.42 & 0.48 & 0.57 & 0.54 & 0.52 & 0.57 & 0.49 & 0.45 \\
\hline & $R_{i}$ & 0.08 & 0.10 & 0.10 & 0.11 & 0.07 & 0.10 & 0.08 & 0.09 & 0.09 & 0.10 \\
\hline & $Q_{i}$ & 0.24 & 0.49 & 0.30 & 0.71 & 0.49 & 0.70 & 0.47 & 0.72 & 0.39 & 0.42 \\
\hline
\end{tabular}

Table 11. The final results with $\rho=0.5$ and $\vartheta \in[0,1]$

\begin{tabular}{|l|c|c|c|c|c|c|c|c|c|c|c|}
\hline$\rho=0.5$ & & $\psi_{1}$ & $\psi_{2}$ & $\psi_{3}$ & $\psi_{4}$ & $\psi_{5}$ & $\psi_{6}$ & $\psi_{7}$ & $\psi_{8}$ & $\psi_{9}$ & $\psi_{10}$ \\
\hline & $S_{i}$ & 0.51 & 0.54 & 0.47 & 0.54 & 0.63 & 0.60 & 0.60 & 0.61 & 0.56 & 0.50 \\
\hline & $R_{i}$ & 0.09 & 0.10 & 0.10 & 0.11 & 0.08 & 0.10 & 0.09 & 0.09 & 0.09 & 0.10 \\
\hline$\vartheta=0.1$ & $Q_{i}$ & 0.21 & 0.66 & 0.62 & 0.94 & 0.10 & 0.70 & 0.43 & 0.43 & 0.27 & 0.64 \\
\hline$\vartheta=0.2$ & $Q_{i}$ & 0.21 & 0.64 & 0.55 & 0.88 & 0.20 & 0.71 & 0.47 & 0.47 & 0.30 & 0.59 \\
\hline$\vartheta=0.3$ & $Q_{i}$ & 0.21 & 0.61 & 0.48 & 0.82 & 0.30 & 0.72 & 0.50 & 0.52 & 0.33 & 0.54 \\
\hline$\vartheta=0.4$ & $Q_{i}$ & 0.21 & 0.58 & 0.41 & 0.76 & 0.40 & 0.73 & 0.54 & 0.56 & 0.36 & 0.49 \\
\hline$\vartheta=0.5$ & $Q_{i}$ & 0.22 & 0.55 & 0.34 & 0.70 & 0.50 & 0.74 & 0.58 & 0.61 & 0.39 & 0.44 \\
\hline$\vartheta=0.6$ & $Q_{i}$ & 0.22 & 0.53 & 0.28 & 0.64 & 0.60 & 0.75 & 0.62 & 0.65 & 0.42 & 0.39 \\
\hline$\vartheta=0.7$ & $Q_{i}$ & 0.22 & 0.50 & 0.21 & 0.58 & 0.70 & 0.77 & 0.66 & 0.70 & 0.45 & 0.34 \\
\hline$\vartheta=0.8$ & $Q_{i}$ & 0.22 & 0.47 & 0.14 & 0.52 & 0.80 & 0.78 & 0.70 & 0.74 & 0.48 & 0.29 \\
\hline$\vartheta=0.9$ & $Q_{i}$ & 0.23 & 0.45 & 0.07 & 0.47 & 0.90 & 0.79 & 0.73 & 0.79 & 0.51 & 0.24 \\
\hline$\vartheta=1$ & $Q_{i}$ & 0.23 & 0.42 & 0.00 & 0.41 & 1.00 & 0.80 & 0.77 & 0.83 & 0.54 & 0.19 \\
\hline
\end{tabular}

\subsection{A comparative analysis}

In this subsection, a comparative study is performed by using the triangular fuzzy AHPVIKOR method (Awasthi et al., 2018) to prove the feasibility of the proposed MCDM framework. The evaluation values provided by suppliers and experts should be denoted as $\bar{R}^{\prime}=\left(\phi_{i j}^{1}\right)_{n \times x}(i=1,2, \ldots, n ; j=1,2, \ldots, x)$ and $R^{k}=\left(\psi_{i j}^{k}\right)_{n \times y}(i=1,2, \ldots, n ; j=1,2, \ldots, y ; k=1,2, \ldots, l$; $x+y=m)$, and $\phi_{i j}^{1}=\left(\alpha_{i j}, \beta_{i j}, \gamma_{i j}\right)$ and $\psi_{i j}^{k}=\left(\alpha_{i j}^{k}, \beta_{i j}^{k}, \gamma_{i j}^{k}\right)$ are TFNs. Therefore, the translated 
scale regarding the evaluation information is provided (see Table 12). Moreover, since the developed method is established based on the suppliers' actual numerical values and experts' evaluation information simultaneously, it is difficult to describe the importance of all the criteria directly. Thus the weight calculated in Subsection 4.1 will be used, and the corresponding $S_{i}, R_{i}$ and $Q_{i}$ can be obtained (see Table 13).

From the results presented in Table 13, we can see that the first condition is satisfied, i.e., $Q_{3}-Q_{7}=0.5-0.23=0.27>\frac{1}{10-1}$. However, the second condition cannot be satisfied. Thus, $\psi_{3}$ and $\psi_{7}$ are the compromise solutions, which are different from the results of the proposed MCDM framework. Thus, $\psi_{3}$ and $\psi_{7}$ are suitable sustainable suppliers if the triangular fuzzy AHP-VIKOR method is used.

The reasons for this phenomenon will now be explained. Firstly, for the triangular fuzzy AHP-VIKOR method, all the SSS criteria should be evaluated subjectively by experts, which may affect the decision-making results. In this study, some criteria can be evaluated in the

Table 12. The translated scale

\begin{tabular}{|c|l|c|l|c|c|}
\hline \multicolumn{3}{|c|}{ Triangular fuzzy VIKOR method } & \multicolumn{3}{c|}{ Picture fuzzy VIKOR method } \\
\hline $\begin{array}{c}\text { Fuzzy } \\
\text { number }\end{array}$ & \multicolumn{1}{|c|}{ Linguistic terms } & $\begin{array}{c}\text { Membership } \\
\text { function }\end{array}$ & Linguistic Term & $\begin{array}{c}\text { Numerical } \\
\text { terms }\end{array}$ & PFN \\
\hline 9 & $\begin{array}{l}\text { Extremely more } \\
\text { important }\end{array}$ & $(7,9,9)$ & $\begin{array}{l}\text { Very very high } \\
\text { (VVH) }\end{array}$ & $0.91-1$ & $(1,0,0)$ \\
\hline 9 & $\begin{array}{l}\text { Extremely more } \\
\text { important }\end{array}$ & $(7,9,9)$ & Very high (VH) & $0.81-090$ & $(0.9,0,0.1)$ \\
\hline 7 & $\begin{array}{l}\text { Very strongly } \\
\text { important }\end{array}$ & $(5,7,9)$ & High (H) & $0.71-0.80$ & $(0.7,0,0.1)$ \\
\hline 7 & $\begin{array}{l}\text { Very strongly } \\
\text { important }\end{array}$ & $(5,7,9)$ & Medium high (MH) & $0.61-0.70$ & $(0.7,0.1,0.2)$ \\
\hline 5 & $\begin{array}{l}\text { Strongly more } \\
\text { important }\end{array}$ & $(3,5,7)$ & Medium (M) & $0.51-0.60$ & $(0.5,0.1,0.1)$ \\
\hline 3 & Weakly important & $(1,3,5)$ & Medium poor (MP) & $0.41-0.50$ & $(0.5,0.2,0.2)$ \\
\hline 3 & Weakly important & $(1,3,5)$ & Poor (P) & $0.31-0.40$ & $(0.3,0.3,0.3)$ \\
\hline 1 & Equally important & $(1,1,3)$ & Very Poor (VP) & $0.01-0.30$ & $(0.1,0.4,0.4)$ \\
\hline 1 & Equally important & $(1,1,3)$ & $\begin{array}{l}\text { Very very Poor } \\
\text { (VVP) }\end{array}$ & 0 & $(0,0,1)$ \\
\hline
\end{tabular}

Table 13. The group utility, individual regret and compromise measure

\begin{tabular}{|c|c|c|c|c|c|c|c|c|c|c|}
\hline & $\psi_{1}$ & $\psi_{2}$ & $\psi_{3}$ & $\psi_{4}$ & $\psi_{5}$ & $\psi_{6}$ & $\psi_{7}$ & $\psi_{8}$ & $\psi_{9}$ & $\psi_{10}$ \\
\hline$S_{i}$ & 0.46 & 0.52 & 0.37 & 0.47 & 0.7 & 0.55 & 0.52 & 0.69 & 0.56 & 0.46 \\
\hline$R_{i}$ & 0.1 & 0.1 & 0.1 & 0.1 & 0.1 & 0.1 & 0.08 & 0.1 & 0.1 & 0.1 \\
\hline$Q_{i}$ & 0.64 & 0.73 & 0.5 & 0.64 & 1 & 0.77 & 0.23 & 0.98 & 0.79 & 0.64 \\
\hline$S$ & 2 & 5 & 1 & 4 & 10 & 7 & 5 & 9 & 8 & 2 \\
\hline$R$ & 2 & 2 & 2 & 2 & 2 & 2 & 1 & 2 & 2 & 2 \\
\hline$Q$ & 3 & 8 & 2 & 5 & 10 & 3 & 1 & 9 & 5 & 3 \\
\hline
\end{tabular}


form of actual data provided by suppliers; while the other criteria can be evaluated subjectively by experts, which is more consistent with the actual decision-making process. Second, compared to TFNs, PFNs are composed of positive, neutral, and negative degrees, which are more suitable for describing comprehensive and uncertain information. Third, the triangular fuzzy AHP-VIKOR method is just an extension of the traditional method. However, the proposed framework considers the grey correlation coefficient, which avoids the shortcomings of the traditional VIKOR method in dealing with small data.

Therefore, the developed framework has more advantages in dealing with SSS problems. Moreover, DMs can choose different parameter values according to their preferences. They can choose smaller parameter values when individual regret is more important, and bigger parameter values can be selected when DMs pay more attention to group utility.

\section{Management implications}

In this section, the management implications of the proposed framework will be summarized. Firstly, SSS plays an important role in the SSCM of enterprises. Based on the existing research, this paper constructed the evaluation criteria of SSS consisting of economic, environmental and social criteria, as well as fourteen sub-criteria. The evaluation criteria can highlight the "sustainable" characteristics and meet the requirements of the new economic environment in China. Secondly, if all of the evaluation information is provided by the suppliers or all of the subjective evaluation information is provided by the experts, then the decision-making process is not reasonable. However, the initial evaluation information consists of the objective information provided by the suppliers and the subjective information provided by the experts simultaneously, which can make the evaluation information more feasible. Taking the criterion cost, i.e., $c_{2}$, as an example, it is the sum of the price of a product and the transaction cost per unit, and all candidate suppliers can provide the cost's specific value. In this case, if the cost is evaluated subjectively by experts using other techniques, then the objectivity of the initial evaluation data will be affected. On the contrary, the inclusion of actual data in the evaluation process can make the final decision more accurate. Thirdly, from the data presented in Table 4, it can be seen that the cost of sustainable supplier $Q_{1}$ selected by the enterprise is relatively high and will not lead to the maximum profit. However, the selected supplier $Q_{1}$ can perform exceptionally in environmental protection, and as a result the $\mathrm{AB}$ enterprise will reduce its overall pollution levels in the future, and increase its utilization rate of sustainable energy to achieve the goal of sustainable development.

Thus, this research has important management implications for managers with regard to strengthening and improving their decision-making with regard to SSS.

\section{Conclusions}

As economies develop, societies progress, competition among enterprises intensifies and there is increasing concern about social responsibility, SSS can play an important role in sustainable development. In this paper, an integrated MCDM framework, based on the picture fuzzy exponential entropy, and extended VIKOR method was proposed to manage SSS problems. First, the evaluation criteria of SSS, including economic performance, environ- 
mental protection, and social responsibility, were summarized. Second, this paper defined the picture fuzzy exponential entropy and proved that it meets the four axiomatic of entropy, which verifies its rationality. Third, based on the proposed picture fuzzy exponential entropy and extended VIKOR method, an integrated MCDM framework with picture fuzzy information was proposed to deal with SSS problems. The picture fuzzy exponential entropy was used to determine the weights of the SSS criteria, whilst the extended VIKOR method was used to rank the sustainable suppliers. Finally, in order to verify the validity and feasibility of the proposed MCDM framework, a sensitivity analysis with different parameter values and a comparison analysis with the triangular fuzzy AHP-VIKOR method were conducted.

The contributions of this paper are as follows: (1) compared with existing extensions of FSs, PFSs can fully describe uncertainty with a positive degree, neutral degree and negative degree for the evaluation values of SSS problems; (2) the picture fuzzy exponential entropy has been investigated, and can be utilized to measure the degree of fuzziness and intuitionism; (3) the proposed MCDM framework can manage some special SSS problems with an unknown criterion weight; (4) the VIKOR method is an effective way of dealing with problems where the types of criteria are in conflict with each other. Moreover, the proposed extended VIKOR method combined with the grey correlation coefficient can overcome the shortcomings of the traditional VIKOR method in data mining.

The main drawback of this research is that the number of DMs involved was small and the interrelationships between the criteria were not taken into account; this may limit the application scope of the proposed framework to some extent. Therefore, further research will need to be conducted in the future, such as considering a larger number of DMs as well as the interrelationships between the SSS's criteria.

\section{Acknowledgements}

The authors are grateful for the suggestions provided by editors and reviewers to improve this paper. This work is supported by the National Natural Science Foundation of China (Nos 71701065, 51875503, 51975512 and 71871228), and Natural Science Foundation of Zhejiang Province (No. LY20G010006).

\section{Disclosure statement}

The authors declare that there is no conflict of interest regarding the publication of this paper.

\section{References}

Aghdaie, M. H. (2017). Data mining group decision-making with fuzzy AHP: An application in supplier evaluation and segmentation. In Fuzzy analytic hierarchy process (pp. 77-102). Chapman and Hall/CRC. https://doi.org/10.1201/9781315369884-4

Alimardani, M., Hashemkhani Zolfani, S., Aghdaie, M. H., \& Tamošaitienè, J. (2013). A novel hybrid SWARA and VIKOR methodology for supplier selection in an agile environment. Technological and Economic Development of Economy, 19(3), 533-548. https://doi.org/10.3846/20294913.2013.814606 
Atanassov, K. (1986). Intuitionistic fuzzy sets. Fuzzy Sets and Systems, 20, 87-96. https://doi.org/10.1016/S0165-0114(86)80034-3

Awasthi, A., Govindan, K., \& Gold, S. (2018). Multi-tier sustainable global supplier selection using a fuzzy AHP-VIKOR based approach. International Journal of Production Economics, 195, 106-117. https://doi.org/10.1016/j.ijpe.2017.10.013

Bai, C. G., \& Sarkis, J. (2010). Integrating sustainability into supplier selection with grey system and rough set methodologies. International Journal of Production Economics, 124(1), 252-264. https://doi.org/10.1016/j.ijpe.2009.11.023

Beskese, A., Kahraman, C., Ender Buyukbay, S., \& Bozbura, F. T. (2018). An intiutionistic fuzzy multiexpert and multi-criteria system for effective performance management. Technological and Economic Development of Economy, 24(6), 2179-2201. https://doi.org/10.3846/tede.2018.6462

Chaharsooghi, S. K., \& Ashrafi, M. (2014). Sustainable supplier performance evaluation and selection with neofuzzy TOPSIS method. International Scholarly Research Notices, 2014, 434168. https://doi.org/10.1155/2014/434168

Cheraghalipour, A., \& Farsad, S. (2018). A bi-objective sustainable supplier selection and order allocation considering quantity discounts under disruption risks: A case study in plastic industry. Computers \& Industrial Engineering, 118, 237-250. https://doi.org/10.1016/j.cie.2018.02.041

Cuong, B. C., \& Kreinovich, V. (2013). Picture fuzzy sets-a new concept for computational intelligence problems. In Proc. of $3 \mathrm{rd}$ World Congress on Information and Communication Technologies (WICT) (pp. 1-6). https://doi.org/10.1109/WICT.2013.7113099

Elkington, J. (1998). Partnerships from cannibals with forks: the triple bottom line of 21 st-century business. Environmental Quality Management, 8(1), 37-51. https://doi.org/10.1002/tqem.3310080106

Goren, H. G. (2018). A decision framework for sustainable supplier selection and order allocation with lost sales. Journal of Cleaner Production, 183, 1156-1169.

https://doi.org/10.1016/j.jclepro.2018.02.211

Hassini, E., Surti, C., \& Searcy, C. (2012). A literature review and a case study of sustainable supply chains with a focus on metrics. International Journal of Production Economics, 140(1), 69-82. https://doi.org/10.1016/j.ijpe.2012.01.042

Ju, Y. B., Ju, D. W., Gonzalez, E. D. R., \& Giannakis, S. M. (2019). Study of site selection of electric vehicle charging station based on extended GRP method under picture fuzzy environment. Computers \& Industrial Engineering, 135, 1271-1285 https://doi.org/10.1016/j.cie.2018.07.048

Kannan, G., Roohollah, K., \& Amin, V. (2015). Intuitionistic fuzzy based DEMATEL method for developing green practices and performances in a green supply chain. Expert Systems with Applications, 42(20), 7207-7220. https://doi.org/10.1016/j.eswa.2015.04.030

Kuo, R. J., Wang, Y. C., \& Tien, F. C. (2010). Integration of artificial neural network and MADA methods for green supplier selection. Journal of Cleaner Production, 18(12), 1161-1170.

https://doi.org/10.1016/j.jclepro.2010.03.020

Liu, K., Liu, Y. W., \& Qin, J. D. (2018). An integrated ANP-VIKOR methodology for sustainable supplier selection with interval type-2 fuzzy sets. Granular Computing, 3(3), 193-208. https://doi.org/10.1007/s41066-017-0071-4

Liu, N., He, Y., \& Xu, Z. (2019a). Evaluate Public-Private-Partnership's advancement using double hierarchy hesitant fuzzy linguistic PROMETHEE with subjective and objective information from stakeholder perspective. Technological and Economic Development of Economy, 25(3), 386-420. https://doi.org/10.3846/tede.2019.7588

Liu, P., Rong, L., \& Teng, F. (2019b). The evaluation of ecosystem health based on hybrid TODIM method for Chinese case. Technological and Economic Development of Economy, 25(3), 542-570. https://doi.org/10.3846/tede.2019.8021 
Luo, L., Zhang, C., \& Liao, H. C. (2019). Distance-based intuitionistic multiplicative MULTIMOORA method integrating a novel weight-determining method for multiple criteria group decision making. Computers \& Industrial Engineering, 131, 82-98. https://doi.org/10.1016/j.cie.2019.03.038

Memaria, A., Dargi, A., Jokar, M. R. A., Ahmad, R., \& Rahim, A. R. A. (2019). Sustainable supplier selection: A multi-criteria intuitionistic fuzzy TOPSIS method. Journal of Manufacturing Systems, 50, 9-24. https://doi.org/10.1016/j.jmsy.2018.11.002

Mou, N. Y., Chang, J. P., \& Chen, Z. S. (2018). Sustainable supplier selection based on Pd-HFLTS and group decision-making theory. Computer Integrated Manufacturing Systems, 24(5), 1261-1278.

Opricovic, S., \& Tzeng, G. H. (2004). Compromise solution by MCDM methods: a comparative analysis of VIKOR and TOPSIS. European Journal of Operational Research, 156, 445-455. https://doi.org/10.1016/S0377-2217(03)00020-1

Osiro, L., Lima-Junior, F. R., \& Carpinetti, L. C. R. (2018). A group decision model based on quality function deployment and hesitant fuzzy for selecting supply chain sustainability metrics. Journal of Cleaner Production, 183, 964-978. https://doi.org/10.1016/j.jclepro.2018.02.197

Peng, H. G., Shen, K. W., He, S. S., Zhang, H. Y., \& Wang, J. Q. (2019). Investment risk evaluation for new energy resources: An integrated decision support model based on regret theory and ELECTRE III. Energy Conversion and Management, 183, 332-348. https://doi.org/10.1016/j.enconman.2019.01.015

Roostaee, R., Izadikhah, M., Lotfi, F. H., \& Rostamy-Malkhalifeh, M. (2012). A multi-criteria intuitionistic fuzzy group decision making method for supplier selection with VIKOR Method. International Journal of Fuzzy System Applications, 2(1), 1-17. https://doi.org/10.4018/ijfsa.2012010101

Sanayei, A., Mousavi, S. F., \& Yazdankhah, A. (2010). Group decision making process for supplier selection with VIKOR under fuzzy environment. Expert Systems with Applications, 37(1), 24-30. https://doi.org/10.1016/j.eswa.2009.04.063

Sarkis, J., \& Dhavale, D. G. (2015). Supplier selection for sustainable operations: a triple-bottom-line approach using a Bayesian framework. International Journal of Production Economics, 166, 177-191. https://doi.org/10.1016/j.ijpe.2014.11.007

Scott, J. A., Ho, W., Dey, P. K., \& Talluri, S. (2014). A decision support system for supplier selection and order allocation in stochastic, multi-stakeholder and multi-criteria environments. International Journal of Production Economics, 166, 226-237. https://doi.org/10.1016/j.ijpe.2014.11.008

Shannon, C. E. (1948). A mathematical theory of communication. Bell System Technical Journal, 27(3), 379-423. https://doi.org/10.1002/j.1538-7305.1948.tb01338.x

Shen, K. W., Li, L., \& Wang, J. Q. (2019a). Circular economy model for recycling waste resources under government participation: a case study in industrial waste water circulation in China. Technological and Economic Development of Economy, 26(1), 21-47. https://doi.org/10.3846/tede.2019.11249

Shen, K. W., Wang, X. K., Qiao, D., \& Wang, J. Q. (2019b). Extended Z-MABAC method based on regret theory and directed distance for regional circular economy development program selection with Z-information. IEEE Transactions on Fuzzy Systems. https://doi.org/10.1109/TFUZZ.2019.2923948

Shen, K. W., \& Wang, J. Q. (2018). Z-VIKOR method based on a new comprehensive weighted distance measure of Z-number and its application. IEEE Transactions on Fuzzy Systems, 26(6), 3232-3245. https://doi.org/10.1109/TFUZZ.2018.2816581

Tavana, M., Shabanpour, H., Yousefi, S., \& Farzipoor, S. R. (2017). A hybrid goal programming and dynamic data envelopment analysis framework for sustainable supplier evaluation. Neural Computing and Applications, 28(12), 3683-3696. https://doi.org/10.1007/s00521-016-2274-z

Tian, C., \& Peng, J. J. (2020). An integrated picture fuzzy ANP-TODIM multi-criteria decision-making approach for tourism attraction recommendation. Technological and Economic Development of Economy, 26(2), 331-354. https://doi.org/10.3846/tede.2019.11412 
Tian, C., Peng, J. J., Zhang, W. Y., Zhang, S., \& Wang, J. Q. (2020). Tourism environmental impact assessment based on improved AHP and picture fuzzy PROMETHEE II methods. Technological and Economic Development of Economy, 26(2), 355-378. https://doi.org/10.3846/tede.2019.11413

Tian, C., Peng, J. J., Zhang, S., Zhang, W. Y., \& Wang, J. Q. (2019). Weighted picture fuzzy aggregation operators and their applications to multi-criteria decision-making problems. Computers \& Industrial Engineering, 137, 106037. https://doi.org/10.1016/j.cie.2019.106037

Trapp, A. C., \& Sarkis, J. (2016). Identifying robust portfolios of suppliers: a sustainability selection and development perspective. Journal of Cleaner Production, 112, 2088-2100.

https://doi.org/10.1016/j.jclepro.2014.09.062

Wang, L., Peng, J. J., \& Wang, J. Q. (2018). A multi-criteria decision-making framework for risk ranking of energy performance contracting project under picture fuzzy environment. Journal of Cleaner Production, 191, 105-118. https://doi.org/10.1016/j.jclepro.2018.04.169

Wang, R., Wang, J., Gao, H., \& Wei, G. (2019a). Methods for MADM with picture fuzzy Muirhead mean operators and their application for evaluating the financial investment risk. Symmetry, 11(1), 6. https://doi.org/10.3390/sym11010006

Weber, C. A., \& Desai, A. (1996). Determination of paths to vendor market efficiency using parallel coordinates representation: a negotiation tool for buyers. European Journal of Operational Research, 1, 142-155. https://doi.org/10.1016/0377-2217(94)00336-X

Weber, C. A., Current, J. R., \& Benton, W. C. (1991). Vendor selection criteria and methods. European Journal of Operational Research, 50, 2-18. https://doi.org/10.1016/0377-2217(91)90033-R

Wei, G. W. (2016). Picture fuzzy cross-entropy for multiple attribute decision making problems. Journal of Business Economics and Management, 17(4), 491-502.

https://doi.org/10.3846/16111699.2016.1197147

Wei, G. (2018). TODIM method for picture fuzzy multiple attribute decision making. Informatica, 29(3), 555-566. https://doi.org/10.15388/Informatica.2018.181

Wei, G., Alsaadi, F. E., Hayat, T., \& Alsaedi, A. (2018). Projection models for multiple attribute decision making with picture fuzzy information. International Journal of Machine Learning and Cybernetics, 9(4), 713-719. https://doi.org/10.1007/s13042-016-0604-1

Wei, G. \& Gao, H. (2018). The generalized Dice similarity measures for picture fuzzy sets and their applications. Informatica, 29(1), 107-124. https://doi.org/10.15388/Informatica.2018.160

Wang, L., Zhang, H. Y., Wang, J. Q., \& Wu, G. F. (2019b). Picture fuzzy multi-criteria group decisionmaking method to hotel building energy efficiency retrofit project selection. RAIRO-Operations Research, 54(1), 211-229. https://doi.org/10.1051/ro/2019004

Wang, L., Wang, X. K., Peng, J. J., \& Wang, J. Q. (2020). The differences in hotel selection among various types of travellers: A comparative analysis with a useful bounded rationality behavioural decision support model. Tourism Management, 76, 103961. https://doi.org/10.1016/j.tourman.2019.103961

Xu, Z., Qin, J. D., Liu, J., \& Martínez, L. (2019). Sustainable supplier selection based on AHPSort II in interval type-2 fuzzy environment. Information Sciences, 483, 273-293. https://doi.org/10.1016/j.ins.2019.01.013

Yu, C., \& Wong, T. N. (2015). An agent-based negotiation model for supplier selection of multiple products with synergy effect. Expert Systems with Applications, 42, 223-237.

https://doi.org/10.1016/j.eswa.2014.07.057

Yu, C. X., Shao, Y. F., Wang, K., \& Zhang, L. (2019). A group decision making sustainable supplier selection approach using extended TOPSIS under interval-valued Pythagorean fuzzy environment. Expert Systems with Applications, 12, 11-17. https://doi.org/10.1016/j.eswa.2018.12.010 
Zhang, X. Y., Wang, J. Q., \& Hu, J. H. (2018). On novel operational laws and aggregation operators of picture 2-tuple linguistic information for MCDM problems. International Journal of Fuzzy Systems, 20(3), 958-969. https://doi.org/10.1007/s40815-017-0441-8

Zadeh, L. A. (1965). Fuzzy sets. Information and Control, 8, 338-353. https://doi.org/10.1016/S0019-9958(65)90241-X

Zhang, S., Wei, G., Gao, H., Wei, C., \& Wei, Y. (2019a). EDAS method for multiple criteria group decision making with picture fuzzy information and its application to green suppliers selections. Technological and Economic Development of Economy, 25(6), 1123-1138. https://doi.org/10.3846/tede.2019.10714

Zhang, S., Gao, H., Wei, G., Wei, Y. \& Wei, C. (2019b). Evaluation based on distance from average solution method for multiple criteria group decision making under picture 2-tuple linguistic environment. Mathematics, 7(3), 243. https://doi.org/10.3390/math7030243

Zhou, X., Pedrycz, W., Kuang, Y., \& Zhang, Z. (2016). Type-2 fuzzy multi-objective DEA model: An application to sustainable supplier evaluation. Applied Soft Computing, 46, 424-440.

https://doi.org/10.1016/j.asoc.2016.04.038 